\title{
Using the Agricultural Policy/ Environmental eXtender to develop and validate physically based indices for the delineation of critical management areas
}

\author{
A. Mudgal, C. Baffaut, S.H. Anderson, E.J. Sadler, N.R. Kitchen, K.A. Sudduth, and R.N. Lerch
}

\begin{abstract}
Targeting critical management areas (CMAs) within cropped fields is essential to maximize production while implementing alternative management practices that will minimize impacts on water quality. The objective of this study was to develop physically based indices to identify CMAs in a 35 ha $(88 \mathrm{ac})$ field characterized by a restrictive clay layer occurring within the upper 15 to $100 \mathrm{~cm}$ (6 to $40 \mathrm{in}$ ) and under a corn (Zea mays L.)-soybean (Glycine $\max$ L.) crop rotation since 1991. Thirty-five subareas were defined based on slope, depth to claypan (CD), and soil mapping units. The Agricultural Policy/ Environmental eXtender (APEX) model was calibrated and validated from 1993 to 2002 using measured runoff, sediment, and atrazine loads, and crop yields. CMAs were delineated based on simulated subarea runoff, sediment, and atrazine loads. Correlation analysis was performed between simulated output by subarea and physical parameters, including CD, surface saturated hydraulic conductivity (Ksat), and subarea slope (SL). Two indices were developed, the Conductivity Claypan Index $(\mathrm{CCI}$; $\mathrm{CD} \times \mathrm{Ksat} \div \mathrm{SL})$ and the Claypan Index (CPI; CD $\div \mathrm{SL}$ ), to correlate with simulated crop yields, runoff, atrazine, and sediment loads. Together, these indices captured 100\% of CMAs for simulated runoff and sediment yield and 60\% of CMAs for simulated atrazine in surface runoff, as predicted by APEX. These critical areas also matched lower corn productivity areas. Management scenarios were simulated that differentiated the management of the CMAs from the rest of the field. Indices, such as these, for identifying areas of higher environmental risk and lower productivity could provide objective criteria for effective targeting of best management practices.
\end{abstract}

Key words: APEX — critical areas—index—modeling — targeting

\begin{abstract}
There have been many efforts and improvements to minimize the impact of nonpoint source (NPS) pollutants on various water bodies, including implementation of different management practices. While working at small scales (e.g., plots or fields), these practices demonstrate positive results in relation to the reduction of NPS pollution. However, at larger scales (e.g., watersheds), many studies have shown very little water quality improvement following implementation of best management practices (BMPs) (Park et al. 1994; Inamdar et al.2002; Simpson and Weammert 2008; Meals et al. 2010). Many factors could diminish the impact of BMPs at the watershed outlet, including not targeting critical areas, hydrologic lag time
\end{abstract}

should be based on easily available and physically measured parameters. Such parameters may include soil characteristics, topographic variables, management, or upstream area.

Walter et al. (2000) defined CMAs in the New York water supply watershed as the flat areas, particularly at the base of hill slopes. These areas were characterized by excessive lateral flow because upstream steep slopes have high infiltration capacity and are underlain by a low permeability, restrictive layer, typically a fragipan or bedrock. As a result, there was little runoff from these slopes but significant subsurface flow. The bottom flat areas became prone to saturation because of incoming subsurface flow and thus to saturation-excess runoff (Hewlett and Hibbert 1967). In contrast, Mudgal et al. (2010b) suggested that in the claypan region of Missouri the backslope was the landscape position most critical for runoff generation and subsequently for NPS transport. This was attributed to the presence of a very shallow top soil horizon over a restrictive high clay content layer with low hydraulic conductivity, known as a claypan. These different studies demonstrate that the location of these critical areas and the selection of the parameters that define them are dependent on the local hydrology, topography, soils, weather, and agricultural practices. Therefore, parameters used for delineation of CMAs are likely to be location specific.

There have been a few indices developed for delineation of critical areas and for studying the hydrologic behavior of specific locations. Heathwaite et al. (2000) developed indices for targeting critical areas that generate and transport excess nutrients in a mixed management watershed located in Pennsylvania.They considered the proximity of areas to streams and the factors influencing saturation-excess runoff generation as the transport factors. Fertilizer application method and rate, phosphorus $(\mathrm{P})$ and nitrogen $(\mathrm{N})$ levels in soils, and

Ashish Mudgal is a scientific business analyst at Monsanto, Saint-Louis, Missouri. Stephen H. Anderson is a full professor in the Department of Soil, Environmental, and Atmospheric Sciences, University of Missouri, Columbia, Missouri. Claire Baffaut is a research hydrologist, E. John Sadler is research leader, Newell R. Kitchen is a soil scientist, Kenneth A. Suduth is an agricultural engineer, and Robert $N$. Lerch is a soil scientist at the Agricultural Research Service Cropping Systems and Water Quality Research Unit in Columbia, Missouri. 
application method of organic fertilizer were considered source factors (Gburek et al.2000). Based on source and transport potential of $\mathrm{N}$ and/or P, the authors delineated and ranked critical source areas. They found that critical areas for P loadings were in close proximity to streams whereas a majority of critical areas for $\mathrm{N}$ loadings were on the outer boundaries of the watershed.

This type of approach for delineation of CMAs was more subjective while other methods, such as the Topographic Wetness Index (TWI; Beven and Kirkby 1979) and its many modified versions (Hjerdt et al. 2004; Ibbitt and Woods 2004; Sorensen et al. 2006; Grabs et al. 2009), are more physically based. The TWI is calculated as a function of local slope and upslope drainage area and has been used in combination with other indices and tools to determine critical areas of a watershed (Tomer et al. 2003; Easton et al. 2008). Fraisse et al. (2001) considered the potential of TWI, elevation, slope, and apparent soil electrical conductivity ( $\mathrm{EC}_{\mathrm{a}}$ ) to explain crop yield variability in a field with claypan soils and found that elevation and soil $\mathrm{EC}_{\mathrm{a}}$ were the most important factors. Kitchen et al. (2005b) confirmed their findings and concluded that productivity zones developed from the field's measured crop yield maps agreed with the management zones delineated using elevation and soil ECa data.

Simulation models have also been used for delineating areas critical for generating and transporting higher amounts of runoff and NPS pollutants. Young et al. (1989) used the Agricultural Nonpoint Source Pollution model (AGNPS) for two watersheds in Winona and Big Stone counties in Minnesota. To apply this grid-based model, they divided the watershed into 0.4 to 16 ha (1 to $39.5 \mathrm{ac}$ ) geographic cells. Areas generating higher sediments, nutrients (total $\mathrm{N}$ and $\mathrm{P}$ ), and runoff were classified as critical areas and were targeted for BMP installation. Endreny and Wood (2003) used an Export Coefficient Model coupled with geographic information system raster maps to delineate phosphorus-critical loading areas in New York's West Branch Delaware River Watershed. A Contributing Area and Dispersal Area weighting function was developed for predicting spatial patterns of P loadings; the Contributing Area and Dispersal Area weighting function was based on landscape position, run-on from upslope areas, and availability of trapping opportuni- ties. They successfully classified these areas into three parts: (1) areas where pollutants were present, (2) areas vulnerable to pollutant transport with runoff, and (3) areas with likelihood of trapping pollutants using buffers. The resulting CMAs generally matched what was observed in the field.

Srinivasan et al. (2005) compared two physically based models, the Soil and Water Assessment Tool (SWAT) and the Soil Moisture Distribution and Routing model, for delineating critical source areas (similar to CMAs) for runoff generation and P transport. Busteed et al. (2009) used the SWAT model to target critical source areas generating higher amounts of sediment and P loads in the Wister Lake Basin, Oklahoma. They found that just $10 \%$ of the basin was generating $85 \%$ of the total NPS pollutants. Using that information, they were able to target specific agricultural producers and enroll them in their water quality program, thus improving the cost effectiveness of limited cost share funds. The Agricultural Policy/ Environmental eXtender (APEX) model, a model from the same family as SWAT, has been extensively used to estimate the effects of agricultural lands, forest lands, and dairy and meat farming on runoff, sediment yield, herbicide loads, and nutrient loads (Saleh et al. 2004; Williams et al. 2006; Wang et al.2007; Wang et al. 2009; Yin et al. 2009; Gassman et al. 2010). In many of these studies, different BMPs were analyzed for their potential to reduce pollutant transport to the streams at subarea or watershed levels (Qiu et al. 2002; Paudel et al. 2003; Harman et al. 2004; Willis 2008). However, the APEX model has never been used for studying in-field variability of environmental and agronomic risk.

Ideally, the delineation of CMAs should be based upon easily accessible physical parameters rather than based on complex and technical procedures that are more costly and time consuming (Wang and Cui 2005). However, because of the complexity of delineating CMAs and their dependence upon many parameters, criteria are often simplified to an extent where they lose their primary purpose; therefore, a balance is needed between ease of delineation and accuracy when identifying critical areas (Line and Spooner 1995).

In the present study area, which is characterized by claypan soils, Lerch et al. (2005) found that surface runoff was a main hydrologic process causing excessive losses of NPS pollutants. Ghidey et al. (1997, 2005, 2010) and Ghidey and Alberts (1999) concluded that in claypan soils runoff events immediately following herbicide and/or fertilizer application were most risky for excessive losses of these constituents to the downstream area and water bodies. Therefore, it could be considered that runoff and related NPS pollutant transport were the most important processes to be controlled in claypan soils for minimizing environmentally hazardous impacts on downstream areas and water bodies.

Mudgal et al. (2010b) provided background for the present study, namely that the APEX model indicates that, in claypan soil landscapes, the backslope position generates and transports higher amounts of runoff and greater atrazine loads than other landscape positions. This landscape position typically has a shallower depth to claypan (CD), lower surface saturated hydraulic conductivity (Ksat), and steeper slope (SL). Hence, the hypothesis for the present study was that these three physically based parameters, CD, Ksat, and SL, could be used as the basis for the delineation of CMAs in claypan soils. Keeping the above hypothesis in mind, the study was done with two main objectives: (1) delineate CMAs that generate disproportionate amounts of runoff, sediment, and atrazine and (2) identify combinations of physically based soil and land parameters that correlate well with simulated runoff, sediment, and atrazine loadings as well as measured crop yields and thus could be the basis for an index to be used for CMA delineation in claypan soils.

\section{Materials and Methods}

Study Area and Cropping System. The study was conducted in a 35 ha $(88 \mathrm{ac}$ ) agricultural field (figure 1) managed by the USDA Agricultural Research Service Cropping Systems and Water Quality Research Unit in Columbia, Missouri. This field is located in the Goodwater Creek Experimental Watershed (GCEW), a 7,250 ha (17,920 ac) agricultural area in north-central Missouri. The predominant soils in the watershed are claypan soils (fine, smectitic, mesic, Aeric Vertic Epiaqualfs and Vertic Albaqualfs). This watershed is part of the Central Claypan Areas (Major Land Resource Area 113), which encompass about 3 million ha (8 million ac) in Missouri and Illinois (USDA NRCS 2006). Claypan soils have a slowly permeable layer generally occurring 8 to 50 


\section{Figure 1}

Location of study site $\left(39^{\circ} 13^{\prime} 48^{\prime \prime} \mathrm{N}, 92^{\circ} 7^{\prime} 12^{\prime \prime} \mathrm{W}\right)$ and study field divided into 35 different subareas with each subarea having homogenous depth to claypan and soil type.

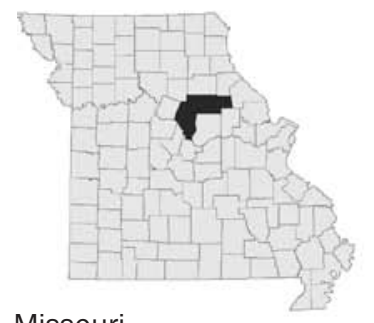

Missouri

\section{Field outlet}

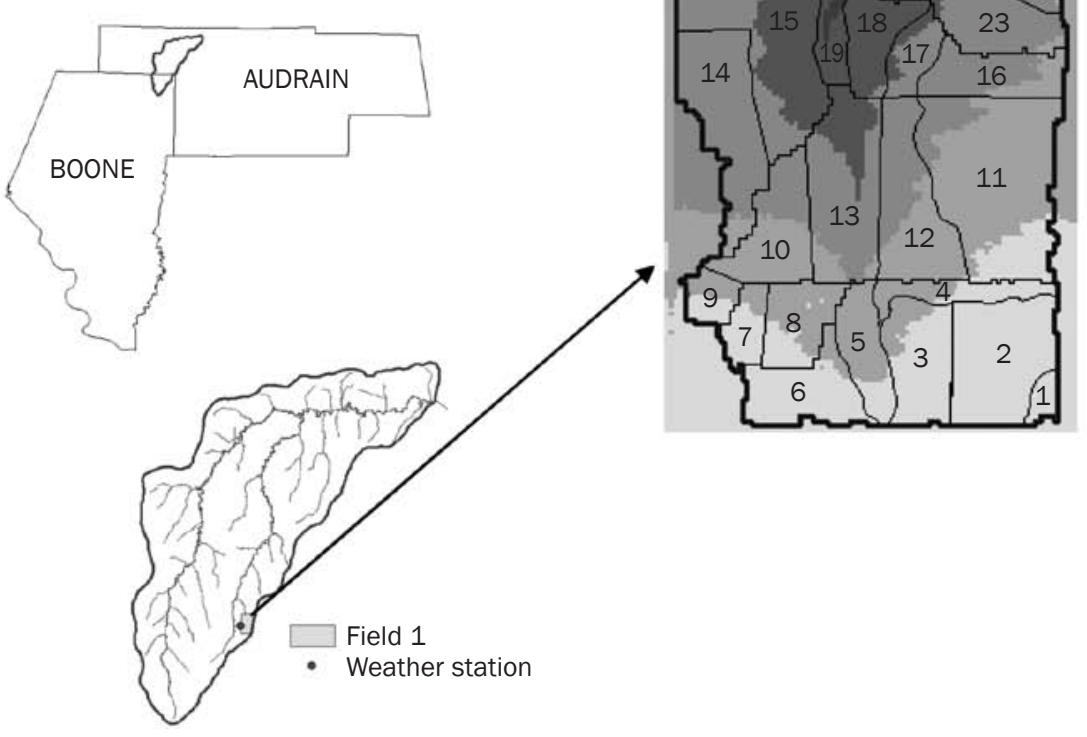

\section{Legend}
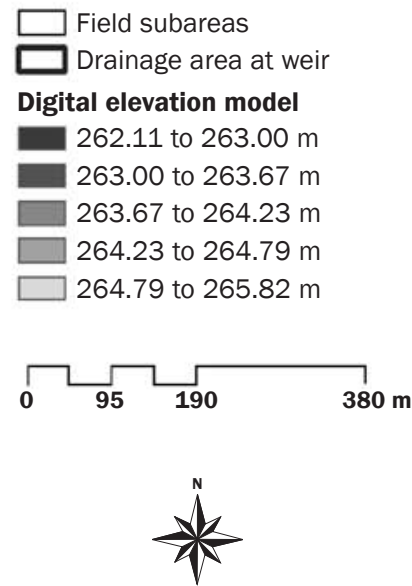

$\mathrm{cm}$ (3 to 20 in) below the surface and having much higher clay content than the overlying material (Blanco-Canqui et al. 2002; Lerch et al. 2005). In specific instances, the claypan layer may be shallower or deeper due to erosion or deposition, respectively. In this field, the claypan was found approximately $15 \mathrm{~cm}$ (6 in) below the surface in the most eroded areas to $100 \mathrm{~cm}$ (40 in) deep in the deposition areas. The claypan controls the hydrology of the field by impeding the vertical flow of water, leading to increased surface runoff (Kitchen et al. 1999; Jung et al. 2005). In addition, it limits the active available water-holding capacity of the soil profile to that which is above the claypan. Average annual precipitation at the study site is 968 $\mathrm{mm}$ (38.1 in), and average annual minimum and maximum daily temperatures are $6.3^{\circ} \mathrm{C}$ and $16.9^{\circ} \mathrm{C}\left(43.3^{\circ} \mathrm{F}\right.$ and $\left.62.5^{\circ} \mathrm{F}\right)$, respectively, based on 30 years of observed data from 1978 to 2007. Historically, corn (Zea mays L.), soybean (Glycine max L.), grain sorghum
(Sorghum bicolor L.), and wheat (Triticum aestivum L.) crops were grown using plow and disk tillage in the northern three-fourths of the field. The southern one-fourth was pastured until 1981 when the whole field was cropped for soybean, grain sorghum and wheat under disk and field cultivator. From 1991 until 2002, the field was under uniform management with a corn-soybean rotation and mulch tillage (Lerch et al. 2005).

Runoff Measurement and Sample Analysis. A 3:1 broad-crested, precalibrated v-notch weir was constructed at the field outlet (figure 1) in 1991 and was instrumented with a runoff water stage recorder and a refrigerated automated pumping sampler (ISCO 3230, Teledyne Isco Inc., Lincoln, Nebraska). The actual drainage area at the weir was 32 ha $(80 \mathrm{ac})$. Water stage was recorded at a 5-minute interval and aggregated to obtain daily values. Threshold value for triggering the runoff sample collection was $0.8 \mathrm{~mm}$ (0.03 in) after which up to 24 separate samples were collected per event, with each sample representing a composite of up to three $100 \mathrm{~mL}(3.4 \mathrm{oz})$ sips collected at a discharge interval of $0.82 \mathrm{~mm}$ (0.032 in), thus characterizing up to $59 \mathrm{~mm}$ (2.3 in) of runoff. Samples were then refrigerated, transported to the laboratory, and analyzed for atrazine (6-chloro-2-ethyl-4[1-methylethyl]-1,3,5-triazine-2,4-diamine) and suspended sediment concentrations. Details on the sampling and atrazine analysis methods were discussed in Lerch et al. (2005) and Ghidey et al. (2010). Sediment concentrations were determined by the evaporation method, as described in Dendy et al. (1979). Samples were weighed and allowed to settle undisturbed, after which excess liquid was decanted from the top of the sample. The remainder of the sample was then transferred to an evaporating dish, oven-dried, and weighed. The data collected from 1993 to 2002 were used for this study including daily runoff, sediment, and atrazine. An automated 
Table 1

Measured soil properties as input in the model.

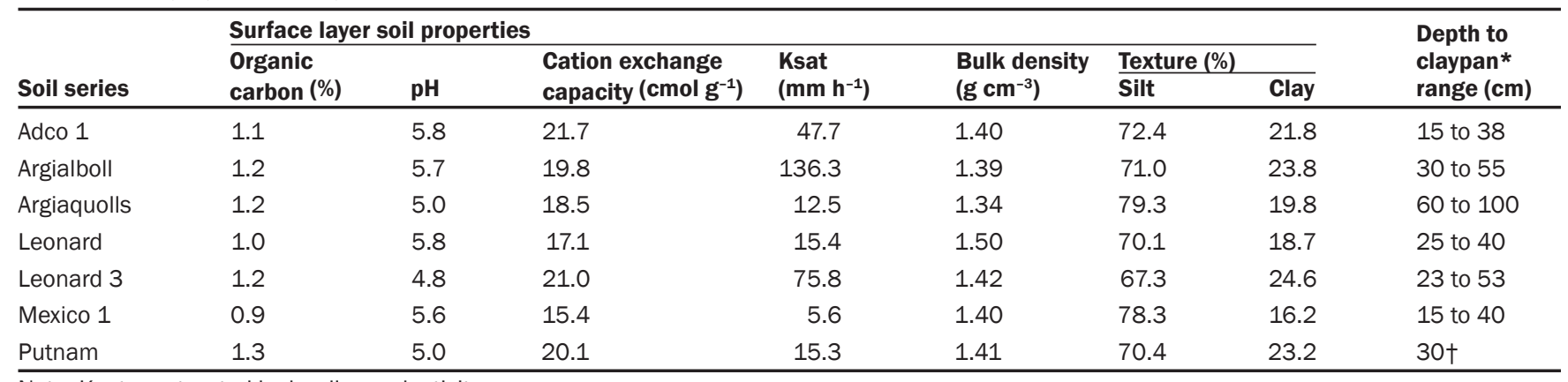

Note: Ksat = saturated hydraulic conductivity.

* Estimated from apparent soil electrical conductivity $\left(\mathrm{EC}_{\mathrm{a}}\right)$ measurements.

$\dagger$ No range as there was only one subarea with Putnam soil.

weather station was installed in the field in 1991, from which hourly rainfall (mm), temperature $\left({ }^{\circ} \mathrm{C}\right)$, average solar radiation $\left(\mathrm{MJ} \mathrm{m} \mathrm{m}^{-2}\right.$ ), relative humidity (fraction), and wind speed $\left(\mathrm{mm} \mathrm{h}^{-1}\right)$ data were collected, recorded and maintained in a server database managed by USDA Agricultural Research Service Cropping Systems and Water Quality Research Unit at the University of MissouriColumbia (Sadler et al. 2006).

Soil, Elevation, and Crop Yield Data Collection. An order 1 soil survey (1:5,000 scale) was conducted in the field during 1997 , and the field was categorized into seven different soil series (figure 2). Soil properties, including texture, cation exchange capacity, organic carbon content, sum of bases, and $\mathrm{pH}$, for four to six horizons in each soil profile had been measured at nineteen points spread around the field during earlier studies (i.e., Sudduth et al. 2003, 2005). Soil hydraulic properties, including field capacity and wilting point, had been measured at these same points by Jiang et al. (2007), and saturated hydraulic conductivity (Ksat) and bulk density had been measured by Mudgal et al. (2010a). Major soil properties for each soil series are presented in table 1 .

Apparent electrical conductivity $\left(\mathrm{EC}_{\mathrm{a}}\right)$ is a sensor-based parameter that is relatively easy to measure in comparison to other soil physical and chemical properties. Soil EC is affected by soil physical properties, including clay content, clay mineralogy, and/or soil moisture content, and provides an indirect measurement of these properties (Kachanoski et al. 1998; Rhoades et al. 1976). Sudduth and Kitchen (2006) and Sudduth et al. (2010) found $\mathrm{EC}_{\mathrm{a}}$ data highly correlated with $\mathrm{CD}$ at the present study site. In this study, CD was estimated using the best field-specific regression equation given in Sudduth et al. (2006).

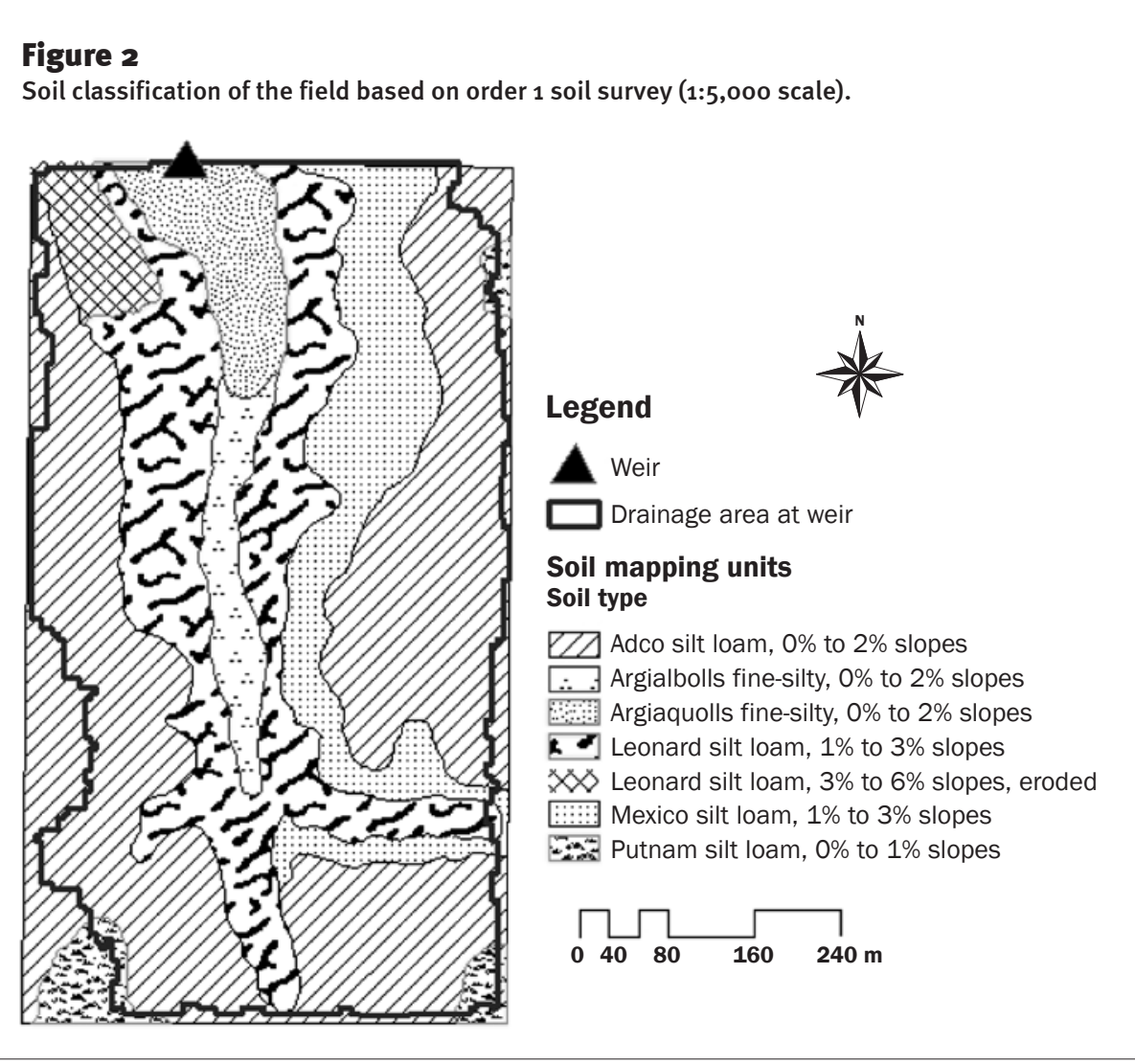

Independent data for this regression were the inverse of the shallow measurement channel of a DUALEM-2S EC sensor (i.e., $\mathrm{EC}_{\mathrm{a}}^{-1}$ ) (Dualem Inc., Milton, Ontario, Canada), and dependent data were measured CD from 19 baseline sites within the field. The regression was then applied to mobile $\mathrm{EC}_{\mathrm{a}}$ data collected on transects spaced $10 \mathrm{~m}(32.8 \mathrm{ft})$ apart with a 4 to $6 \mathrm{~m}$ (13.1 to $19.7 \mathrm{ft}$ ) data spacing to generate a spatially dense CD estimate (Kitchen et al. 2005a; Sudduth et al. 2005).
Additional data included elevation data (vertical accuracy 3 to $5 \mathrm{~cm}$ [1.2 to 2 in]) collected during previous studies using a realtime kinematic global positioning system survey on $10 \mathrm{~m}$ (32.8 ft) transects (Fraisse et al. 2001; Kitchen et al. 2005a). The data were processed into a digital elevation model (DEM) from which slopes were calculated using ArcInfo 9.2. Spatially distributed crop yields were measured from 1993 to 2002 using combines with commercially available yield sensing systems as explained in Kitchen 
et al. (2005a). The data were collected at a 1 -second interval and generally interpolated to a $10 \mathrm{~m}$ resolution to create productivity maps using methods and software described by Sudduth and Drummond (2007).

\section{Agricultural Policy/Environmental} eXtender Model Setup. APEX is a field/ watershed scale model that provides flexibility to define weather, land use, soils, topography, and management practices such as tillage, crop rotations, and agricultural inputs. The model is a powerful tool to estimate the impact of different management scenarios on erosion, water quantity and quality, and soil organic carbon, and simulates the fate and transport processes for runoff, sediment, nutrients and herbicides/pesticides (Saleh et al. 2004; Wang et al. 2006). APEX performs these processes across complex landscapes, routing constituents to the outlet of a small watershed or field through channels, subsurface flow, or groundwater (Srivastava et al. 2007; Gassman et al. 2010). In short, runoff is calculated using a modification of the curve number method, in which the curve number is adjusted as a function of a soil moisture index to estimate antecedent moisture conditions. Soil water is subject to evapotranspiration, percolation, and subsurface flow. Erosion is calculated using the MUST variant of the Modified USLE equation (Williams 1995), in which the cover factor is calculated as a function of live biomass and ground cover. Atrazine is subjected to degradation using a first order decay process and can be transported to the outlet with surface runoff and subsurface flow. This study was conducted with the latest APEX version 0604 available in December 2008 and updated with the July 2010 version; a theoretical documentation and a user's manual document how processes are simulated and what input data are needed (Williams et al. 2008; Steglich and Williams 2008).

The first step in APEX model setup was to divide the field into smaller spatial units called subareas represented with homogenous soil and topographic properties. A depth to claypan map was created using the values derived from $\mathrm{EC}_{\mathrm{a}}$ measurement data by classifying these values into 6 classes with the Jenks algorithm available in ArcInfo. Finally, the resulting claypan depth map was intersected with the order 1 soil map of the field. Each resulting polygon with homogenous CD and soil type was treated as one subarea. Using this technique, the field was divided into 35 different subareas (figure 1). The DEM was used in ArcInfo for creating the flow paths in the field that were then used for describing the APEX routing scheme from one subarea to another and to the field outlet.

After subareas were delineated, soil and topographic characteristics were determined for each subarea based on field estimations and soil data. The profiles of the soils were adjusted based on an average estimated CD calculated for each subarea; the range of these depths for each soil series is presented in table 1. The routing channel dimensions were also measured in the field and were input to the model. Weather and management inputs were the same for the whole field. All the weather variables were collected from the weather station situated adjacent to the field from 1991 to 2002 and aggregated to a daily time step.

The field was under uniform management from 1991 to 2002 in a corn-soybean alternate annual crop rotation, where corn was planted during odd years and soybean during even years. The field was under mulch tillage, maintaining around 30\% residue cover with usually one disk and one or two field cultivation passes before the spring planting of the crop. There were exceptions. In 1995, corn was replaced with grain sorghum because of a delay in sowing as a consequence of a very wet spring; an extra fall tillage operation was also added to remediate the soil compaction caused by field operations on wet soils during the spring (Lerch et al. 2005).

Once the model was set up, it was calibrated and validated for event runoff, sediment, and atrazine, where events were defined as one or more days with daily flow equal to or greater than $0.8 \mathrm{~mm}$ (0.03 in) surrounded by days with flow less than 0.8 $\mathrm{mm}$, which was the autosampler triggering threshold. The calibration period was from 1993 to 1997 , and the validation period was from 1998 to 2002. The model's goodness of fit was evaluated through linear regression $\left(r^{2}\right)$, Nash and Sutcliffe (1970) efficiency (NSE), ratio of the root mean square error to the standard deviation of the measured data (RSR), and percent bias (Pbias) calculated on an event basis. These calibration indicators have been extensively used in modeling studies (Ramanarayanan et al. 1997; Santhi et al. 2001; Wang et al. 2007) and are explained in detail by Krause et al. (2005) and Moriasi et al. (2007). Many researchers have considered various acceptable ranges for $r^{2}$,
NSE, and Pbias based upon the amount of available measured data, output time interval, and purpose of the study. Moriasi et al. (2007) provided acceptable ranges for NSE and Pbias when quantifying the accuracy of monthly simulations of watershed runoff and pollutant loadings. Considering an event time step typically yields less accurate simulations than a monthly time step (Moriasi et al. 2007), acceptable values in the present study for calibration and validation were defined as $r^{2}>0.5$, NSE $>0.45$, and RSR $<0.74$. Acceptable values of Pbias were different depending on the model output. For runoff, the selected range was $-25 \%<$ Pbias $<25 \%$; for sediment and atrazine load, it was $-55 \%$ $<$ Pbias $<55 \%$. These ranges resulted from an analysis of uncertainties in measured runoff and load estimates (Harmel et al. 2006) caused by the procedures for flow measurement, sample collection, sample preservation, and laboratory analysis of constituents.

Index Development for Critical Management Area Delineation. Model output of crop yield, runoff, sediment, and atrazine for each subarea were used for CMA delineation, and indices were developed. The CMA designation in the field was based upon the 1993 to 2002 average annual value of the output variable, calculated for each subarea individually. The three parameters: CD, surface Ksat, and SL were estimated for all subareas and were correlated in different combinations with each of the selected model output variables estimated for these subareas. The significance of correlation coefficient $(r)$ values were estimated by using $t$-statistics with $\mathrm{n}-2$ degrees of freedom at the 95\% confidence level (Kaps and Lamberson 2007). The $\mathrm{n}$ value was 35 as there were 35 different subareas delineated for the field and the same number of observations. The $r$-value was considered significant if it was greater than 0.28 with $5 \%$ confidence interval estimated from a one tailed $t$-test. When the correlation factor was significant, the combinations of these parameters were treated as a possible index to be used in future studies for CMA delineation. The combinations of parameters used for $r$-value estimation with selected outputs were $\mathrm{CD}$, surface Ksat, SL, CPI $=\mathrm{CD} / \mathrm{SL}$ (Claypan Index), and CCI $=(\mathrm{CD} \times \mathrm{Ksat}) /$ SL (Conductivity Claypan Index).

A spatial distribution map for each output variable and for each retained index was developed using ArcInfo, and the total range 
of values for all the subareas was divided into five different classes using Jenks' optimization technique or natural break method in ArcInfo. Jenks method (Jenks 1967) attempts to form classes so that the differences between observations within the same class are minimized and the differences between classes are maximized. It attempts to find the natural breaks in a rank-order graph. The Jenks optimization method is also known as the goodness of variance fit. CMAs were then estimated for each output and for each index separately and defined as the subareas that had amounts of output falling in the two most extreme classes, as divided by Jenks method. CMAs obtained for each output variable and for each index were compared based on the percentage of area classified as critical, the percentage of area misclassified as critical, and the percentage of area misclassified as noncritical.

Finally, average crop yields from 1993 to 2002 for corn and soybean were also averaged for each subarea in order to show any relationship between CMAs delineated for environmental hazards and crop productivity from these subareas. The same statistical correlation procedure was used to estimate significant $r$-values between measured and simulated crop yields and the developed indices.

Best Management Practices and Simulation Scenario Analyses. Four BMP scenarios were simulated in the field for the 30-year period from 1979 to 2008 and compared to the baseline, which describes the management that took place between 1991 and 2002. These scenarios represent hypothetical management possibilities to reduce the environmental risk stemming from cropping this field.

In BMP scenario 1, perennial switchgrass (Panicum virgatum L.) was planted on the CMAs, keeping the rest of the field with the same corn-soybean mulch till management. Switchgrass was sown on the 21st of March of the first simulation year and was harvested on September 18th of each subsequent year. Scenario 1 was divided into two parts based on the technique used to delineate the CMAs: in the first part, CMAs were delineated using the model results while in the second part, CMAs were delineated using the indices. The other 3 scenarios were not targeted to CMAs. They represent common conservation practices that are currently used by producers to reduce environmental risk. Scenario 2 is a mitigating practice, i.e., the loss of sediment and nutrients is captured by a filter strip located at the downstream edge of the drainage way. A filter strip of area 1 ha $(2.5 \mathrm{ac})$ was simulated immediately before the field outlet, i.e., in subarea 35 (figure 1) where the soil type is Argiaquoll (table 1). The strip was managed under continuous fescue grass (Festuca L.) that was never harvested during the 30-year simulation period.

Scenarios 3 and 4 are two components of a possible alternative management of the field where the two areas on either side of the channel are in a wheat-soybean rotation, and the channel itself is planted with grass. In scenario 3 , the total field was managed with a wheat-soybean rotation in which soybean production management was similar to that used during calibration and validation. Wheat operations included $\mathrm{N}$ and $\mathrm{P}$ application followed by mulch tillage prior to fall sowing and one more $\mathrm{N}$ application during the spring of the following year. Wheat was harvested in the summer following the fall planting. Scenario 4 had similar crop management as the baseline everywhere in the field but in the channel areas. Those, (subareas 19, 25,33 , and 35) were put under switchgrass and managed the same way as in scenario 1 .

All scenarios involve planting different crops in separate areas of the field, which are expected to result in reduced amounts of runoff, atrazine, and sediment loads through various processes. Crops that belong to distinct land covers (grain versus grass for example) are characterized by different curve numbers that directly impact the amounts of runoff, sediment, and atrazine generated. Crops that grow and use soil water at a different time in the year may also affect runoff. For example, wheat water uptake occurs during fall and spring while corn and soybean take water during the summer. Factors that affect sediment loss are the live biomass and the amount of residues on the ground.APEX calculates the cover factor (USLE_C) as a function of these variables, which will vary from crop to crop. Tillage also affects erosion by removing residues from the ground surface. In addition, sediment transport can be reduced across grass areas that have greater infiltration capacities, slow the flow down, and allow settling of soil particles. These areas are characterized by higher saturated conductivities and Manning $\mathrm{n}$ coefficients. In terms of atrazine load, switching to crops that do not require atrazine eliminates the herbicide amount in those areas and thus the field-scale loss.
Measured daily rainfall and temperature data were used for the whole simulation period, but average daily solar radiation, relative humidity, and wind speed were simulated from 1979 to 1990 because measured data were not available. Monthly characteristics of precipitation, temperature, daily radiation, relative humidity, and wind speed were calculated based on measured weather data from 1991 to 2008. These monthly characteristics were used to simulate missing daily weather data from 1979 to 1990 using the weather generator intrinsic to APEX (Williams et al. 2008). After 1991, all weather variables used in the model were obtained from daily or subdaily measurements. Significance in differences between model outputs from a BMP scenario and the baseline were evaluated using the nonparametric Wilcoxon statistical test (Kaps and Lamberson 2007) with the SAS PROC NPAR1WAY procedure (SAS Institute 1999) at a confidence level of $95 \%(p<0.05)$.

\section{Results and Discussion}

Model Calibration and Validation. Calibration and validation results are presented in figure 3. Model performance ratings for runoff, calculated on an event basis, were strong with $r^{2}$ around 0.80 . NSE values were 0.78 and 0.72 and RSR values were 0.47 and 0.53 , for calibration and validation, respectively. On a daily basis, these criteria were also strong: greater than 0.70 for $r^{2}$ and NSE and less than 0.55 for RSR. Results were in accordance with performance ratings found by various researchers in other APEX studies; Yin et al. (2009) in Huaihe River watershed, Henan province, China, found $r^{2}$ and NSE values of 0.56 and 0.52 at a daily time step, and Williams et al. (2006) had $r^{2}$ values of 0.72 and 0.73 in a Bison feedlot in North Dakota. The $r^{2}$ and NSE values in the simulation study done on claypan soils for 12 different plots (Mudgal et al. 2010b) ranged from 0.52 to 0.98 and 0.46 to 0.94 , respectively; percent bias from $-12 \%$ to $-59 \%$ showed an overprediction of runoff. In contrast, the simulation of surface runoff in this study produced smaller bias: $5.6 \%$ and $23 \%$ for calibration and validation, respectively (figure 3 ).

The model performed very well for atrazine loads, with all calibration criteria better than the minimum set for acceptable results. APEX was able to simulate atrazine load effectively because the atrazine application 


\section{Figure 3}

Comparison of simulated and measured transport for the field: (a) calibration events runoff, atrazine load, and sediment yield (1993 to 1997), and (b) validation events runoff, atrazine load, and sediment yield (1998 to 2002).

(a)
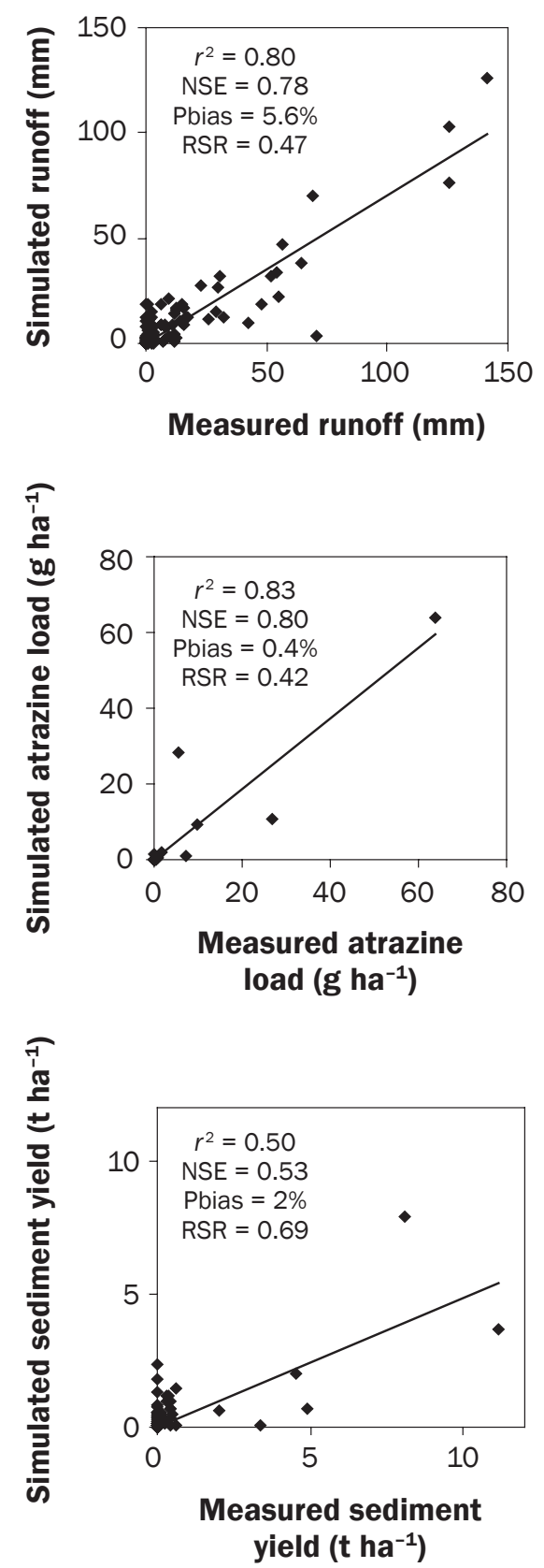

(b)
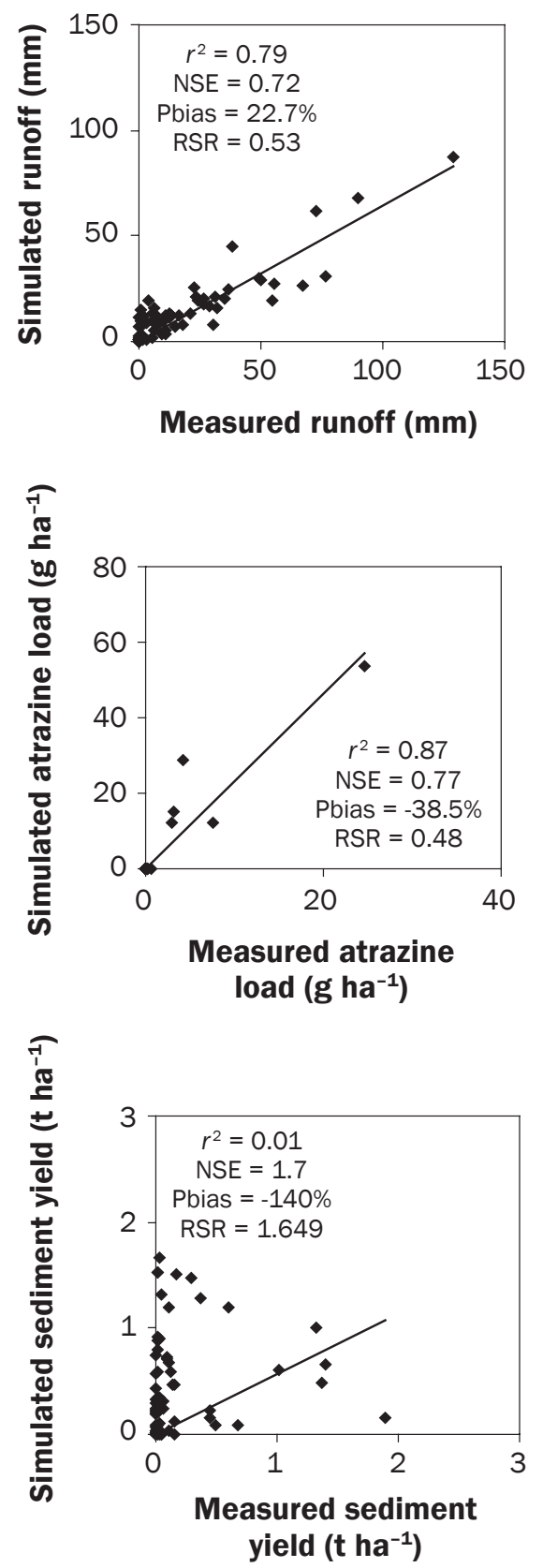

Notes: NSE = Nash-Sutcliffe efficiency. Pbias $=$ percent bias. RSR $=$ is the root square error to standard deviation ratio.

rate and timing were exactly known during the whole simulation period. Also, including a tillage practice just after atrazine application effectively represented the incorporation of atrazine in the field. On the other hand, sediment yields were well simulated during the calibration period but overpredicted during the validation period, especially during the winter. In general, small events were overpredicted while larger events tended to be underpredicted. The validation period did not include any large events of the size that occurred during the calibration period. It was observed in the field that there was always accumulation of sediment just in front of the weir at the field outlet, thus reducing the measured sediment yield in comparison to the actual sediment eroded and transported to the edge of the field.

Flow, sediment, and atrazine loads were higher during the calibration period than during the validation period whether they were measured or simulated. Measured average annual values of sediment and atrazine loads decreased by $67 \%$ and $45 \%$, respectively, while simulated values decreased by $25 \%$ and $24 \%$, respectively. Precipitation decreased by $5 \%$, and average annual values of both measured and simulated flow decreased by $12 \%$. While higher precipitation during the calibration period (1045 mm [42 in] annual average from 1993 to 1997) in comparison to the validation period $(990 \mathrm{~mm}$ [40 in] annual average from 1998 to 2002) may have been a factor, the switch from conventional to mulch tillage implemented in 1991 could also have accentuated the effects. Gradual changes in soil properties caused by the tillage modifications, e.g., organic matter, were not taken into consideration in the model and may explain the differences in calibration indicator values between the calibration and validation periods. In addition, at low flows the weir acted as a small dam, allowing water to pond and sediment to be deposited before it went over the notch, which could result in under-measured loads for the smaller events. One difficulty with the APEX model is the large number of parameters one can adjust, which makes it difficult to determine whether unsatisfactory results are caused by the model itself or its parameterization. Alternatively, it could be that conditions in the field have changed between the calibration and validation periods. Lerch et al. (2005) measured sudden and significant increases in shallow aquifer nitrate concentrations in one of five groundwater wells at this field starting in 1999, a very dry year. Other wells were characterized by increasing and decreasing nitrate concentrations in 2002, another dry year. These sudden changes were attributed to cracks, which developed in the soil profile during dry conditions and extended to the soil surface. The development of these cracks and their impact on the hydrology and pollutant transport in the field was not simulated 


\section{Figure 4}

Critical management areas (CMAs) delineated for study field using APEX model outputs for 1993 to 2002 average annual values of (a) runoff, (b) atrazine load, and (c) sediment yield. The shaded regions in each map were the highest two classes when classified into five classes by the Jenks optimization technique.

(a)

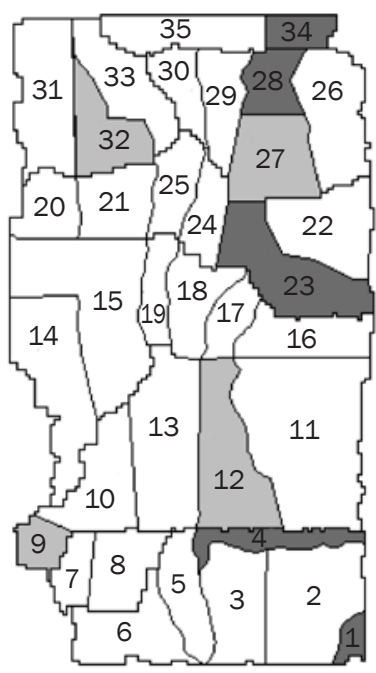

Average annual surface runoff (b)

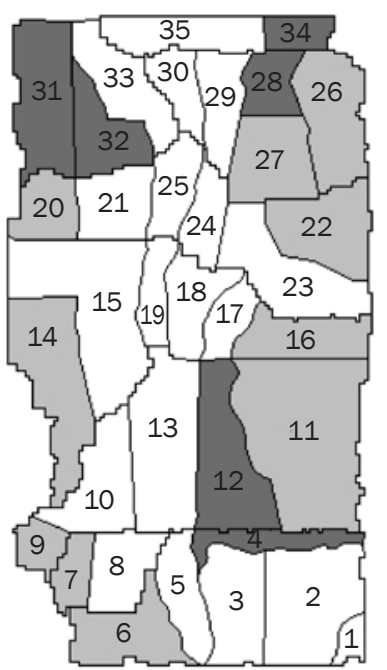

Average annual atrazine load (c)

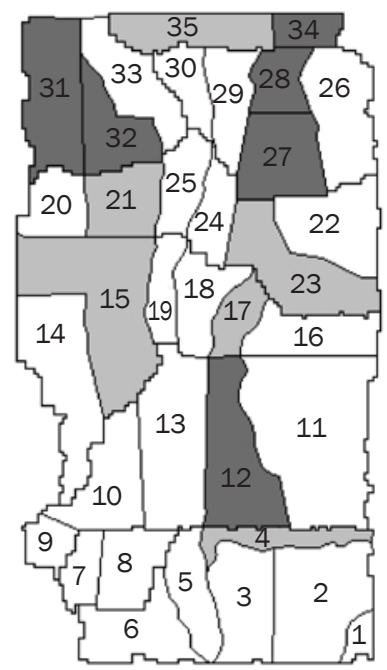

Average annual sediment load
Legend

$$
\begin{aligned}
& <270 \mathrm{~mm} \\
& 270 \text { to } 276 \mathrm{~mm} \\
& >276 \mathrm{~mm}
\end{aligned}
$$

Legend

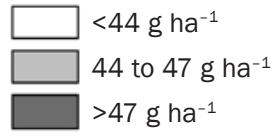

Legend

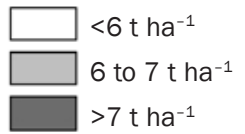

with APEX. Finally, the combination of high clay content soils with a restrictive layer close to the surface and a climate that includes large interannual variations of precipitation may be at the limit of APEX capabilities. Whatever the reason, these validation results for sediment reduce our confidence in the model sediment predictions.

Average annual values of field-average corn and soybean yields measured from 1993 to 2002 were 5.8 and $2.3 \mathrm{t} \mathrm{ha}^{-1}$ (92 and $\left.34 \mathrm{bu} \mathrm{ac}^{-1}\right)$, respectively, whereas area weighted average simulated corn and soybean yields for the same period were 5.9 and $2.1 \mathrm{t} \mathrm{ha}^{-1}$ (94 and $31 \mathrm{t} \mathrm{ac}^{-1}$ ), or $1 \%$ more and $9 \%$ less, respectively. In 1995, sorghum was planted, and the bias between measured and simulated yields in that year was $11 \%$. The temporal variation in simulated yields reflected that of the measured yields with a coefficient of determination $\left(r^{2}\right)$ of 0.74 . The very wet summer of 1993 led to no water stress and the highest measured and simulated corn yields, $7.2 \mathrm{t} \mathrm{ha}^{-1}\left(115 \mathrm{bu} \mathrm{ac}^{-1}\right)$ and $8.2 \mathrm{t} \mathrm{ha}^{-1}\left(130 \mathrm{bu} \mathrm{ac}^{-1}\right)$, respectively. The smallest measured yields were obtained in 1994 and 1999 for soybean and corn yields, respectively. The largest annual bias between measured and simulated yields occurred in $1996(33 \%)$ and $1999(-78 \%)$ for soybean and corn, respectively.

The flow and water quality calibration and validation were based on values measured at the outlet of the field. The only observations available at subarea scale were the crop yields, and we used those to investigate whether the model was responding to changes in slope, Ksat, and CD that characterize the spatial variability of soil properties across the field. The model was able to simulate spatial variations of average 1993 to 2002 corn yields across the 35 subareas with some success $\left(r^{2}\right.$ $=0.20)$. The correlation was strongest during $1997\left(r^{2}=0.26\right)$. However, wet years such as 1993 and 1995 led to no spatial correlation between simulated and measured crop yields. There was also no spatial correlation between average measured and simulated soybean yields. However, the variations in measured soybean yields were also much smaller: the ranges of variation relative to the average yield were $29 \%$ and $18 \%$, for corn and soybean, respectively. During the calibration process, we observed that simu- lated corn yields, as well as flow and water quality at the outlet, were especially sensitive to soil Ksat and CD. Soybean yields, on the other hand, were not. Although smaller than for corn yields, variability in measured soybean yields suggests that other processes than water availability are affecting soybean growth. However, no attempt was made during this study to investigate what these parameters may be.

Critical Management Area Delineation. CMA delineation was based on APEX simulated runoff, sediment, and atrazine 30-year average annual values for individual areas. After classifying the subareas based on these output variables, subareas in the highest two classes for each of them (figure 4) were treated as APEX-based CMAs. Resulting threshold average annual values of model outputs used to delineate critical areas were $270 \mathrm{~mm}$ (10.6 in) for runoff, $44 \mathrm{~g} \mathrm{ha}^{-1}$ (0.039 $\mathrm{lb} \mathrm{ac}$ ) for atrazine loads, and $6 \mathrm{t} \mathrm{ha}^{-1}$ (2.7 tn $\left.\mathrm{ac}^{-1}\right)$ for sediment yields. All the resulting areas with runoff or loads greater than these values were treated as CMAs. Twenty percent of the total field area was found to be critical due to excess runoff generation, $48 \%$ due to 
atrazine load and 35\% due to sediment yield. The total CMA delineated was 66\% $(20.8$ ha $[51.4 \mathrm{ac}])$ of the total field area. While $76 \%$ and $92 \%$ of critical areas for surface runoff were also critical for atrazine and sediment, respectively, close to $70 \%$ and $50 \%$ of critical areas for atrazine and sediment, respectively, were not critical for surface runoff. Thus, in this field, most areas generating higher amounts of surface runoff also generated higher amounts of atrazine and sediment, as determined by the APEX simulation results. Those were the subareas with low permeability (Ksat $<16 \mathrm{~mm} \mathrm{~h}^{-1}\left[0.6 \mathrm{in} \mathrm{hr}^{-1}\right]$ ); only subarea 9 had a higher permeability but very low CD (15 cm [6 in]). Most of these areas had CDs less than $25 \mathrm{~cm}$ (10 in). Areas producing the lowest amounts of runoff, atrazine, and sediment were in and adjacent to the channel and in the south end of the field; all had CDs greater than $25 \mathrm{~cm}$ (10 in) and most had Ksat greater than $47 \mathrm{~mm} \mathrm{~h}^{-1}\left(1.9 \mathrm{in} \mathrm{hr}^{-1}\right)$. Other areas generated high amounts of atrazine or sediment without generating high surface runoff, as shown in figure 4 . Those included subareas on the east and west edges of the field: areas $35,26,22,17,16$, and 11 on the east side and $31,21,20,15,14,7$, and 6 on the west side. Area 31 had a $1.5 \%$ slope, the highest in the field. Others had higher permeability but low CD. Only one, area 17, had low permeability and greater CD. Given the low confidence in sediment results, one may question the validity of the critical areas for sediment. From those, four were not critical for runoff or atrazine: areas $15,17,21$, and 35 . They represent $13 \%$ of the field or $20 \%$ of the APEX-delineated critical areas. Thus, $80 \%$ of the APEX-delineated critical areas were critical for runoff or atrazine independently of the results for sediment.

Runoff generation from any subarea was found to be highly dependent on the surface Ksat $(r=-0.66)$ and to CD $(r=-0.50)$. Depth to claypan was more important for atrazine loss $(r=-0.59)$ while sediment was most correlated with Ksat $(r=-0.41)$. In APEX, runoff is calculated as a function of the retention using the curve number method. However, several adjustments can be made to either the curve number or the retention parameter to account for slope, soil water content, and frozen soils. Most important to this study is the adjustment of the retention parameter with soil water content. Retention is adjusted as a function of soil water content, retention associated to dry conditions (mois- ture condition 1), and two shape parameters, which are set so that retention is equal to average condition retention (moisture condition 2) when soil water content is $60 \%$ of field capacity and equal to wet condition retention (moisture condition 3) when available water is half that at saturation. Soil water content is itself adjusted based on plant water uptake, vertical flow (i.e., percolation and evaporation), and lateral flow, which includes subsurface flow to the nearest downstream subarea and quick return flow to the channel. Williams et al. (2009) provide equations for all the simulated processes. Without going into details, percolation and lateral flow are functions of Ksat, water content at field capacity, porosity, soil layer thickness, and soil layer water content. While the model allows for user-specified soil water contents at field capacity and wilting point, those were left blank and thus estimated by the model with the Rawls method (Saxton et al. 1986). In addition to these parameters, slope steepness and slope lengths intervene in the calculation of horizontal travel time. Finally, the partition of lateral flow between subsurface flow and quick return flow is a function of the slope length relative to the channel length. Once vertical and lateral movements are calculated, remaining excess water is transferred back to the layer above, all the way through to the top layer and surface runoff if necessary. This may occur when hydraulic conductivities are too small to route excess water or when bottom layers become saturated.

In this case of shallow CD and low Ksat, it was expected that Ksat, layer thickness, and slope would be sensitive parameters. Porosity and field capacity, which were estimated by the model as a function of texture, were relatively homogeneous throughout the field and were less sensitive. This may be important to revisit in an area where these two parameters are not uniform.

Index Development. The results of this and other studies done in similar soils (Kitchen et al. 2005b; Lerch et al. 2005; Fraisse et al. 2001; Kitchen et al. 1999) confirm that the $\mathrm{CD}$ is an important parameter, impacting not only the generation of NPS pollutants and runoff but also the crop yield. In the present study, the coefficients of correlation $(r)$ between CD and generated runoff, sediment yield, and atrazine load were -0.50 , -0.35 , and -0.59 , respectively. After including the slope factor with $\mathrm{CD}$, thus creating the Claypan Index (CPI), the relationship wors- ened for runoff $(r=-0.28)$, strengthened for sediment yield at $(r=-0.50)$, and remained similar for atrazine load to $(r=-0.56)$. CPI was able to delineate CMAs that generated the highest sediment yield and atrazine load. By multiplying CPI by Ksat, a new index was developed and called the Conductivity Claypan Index (CCI). CCI was best at identifying runoff CMAs $(r=-0.69)$ and worse for atrazine $(r=-0.39)$. Thus CD may be the dominating factor for atrazine transport. Coefficients of correlation $(r)$ and scatter plots between model outputs and index values are shown in figure 5 . As simulated environmental variables were negatively correlated with these proposed indices, lower values of either index implied higher environmental risk, and subareas having values in the lowest two classes of indices were treated as index-based CMAs as shown in figure 6 . CMAs delineated with these two indices were able to capture $71 \%$ of CMAs delineated by the model outputs (figure 4).

Both indices were positively correlated with corn yields (table 2 ), and especially with simulated corn yields $(r>0.6)$. The positive correlation was expected because lower values of these indices are indicative of more sensitive areas that are likely to be less productive. In addition, correlation between each index and measured corn yields was verified (table 2), thus confirming that increased estimated environmental risk goes along with observed decreased corn yields in this field. Since we do not have measured data to assess the spatial variability of the environmental risk across the field, crop yields are our best surrogate for it. For corn, CPI performed slightly better than CCI, as indicated by the correlation coefficients. For soybeans, the only significant correlation was between CCI and simulated soybean yields. Again, there was also lower variability in measured soybean yield in the field as estimated by Kitchen et al. (2005a). This lower variability could be attributed to reduced water demand of soybean compared to corn (Thompson et al. 1991).

Following analysis of productivity data in the field, Kitchen et al. (2005b) hypothesized that $\mathrm{EC}_{\mathrm{a}}$ and elevation could be used to delineate productivity zones, dividing the field into 3 zones. Management zone A, where crop production had not been profitable for much of the area, encompasses the area north of the east-west line formed by the southern boundary of subareas 16 to 18 , excluding the channel subareas 19, 24, 25, 


\section{Figure 5}

Scatter plots and coefficients of correlation $(r)$ between average annual runoff, sediment yield, and atrazine load. (a) $\mathrm{CPI}=\mathrm{CD} \div \mathrm{SL}$ and (b) $\mathrm{CCI}=\mathrm{CD} \times \mathrm{Ksat} \div \mathrm{SL}$, where $\mathrm{CPI}=\mathrm{Claypan}$ Index, $\mathrm{CCI}=$ Conductivity Claypan Index, $\mathrm{CD}=$ depth to claypan, $\mathrm{Ksat}=$ saturated hydraulic conductivity of the surface soil layer, and SL = average slope.

(a)
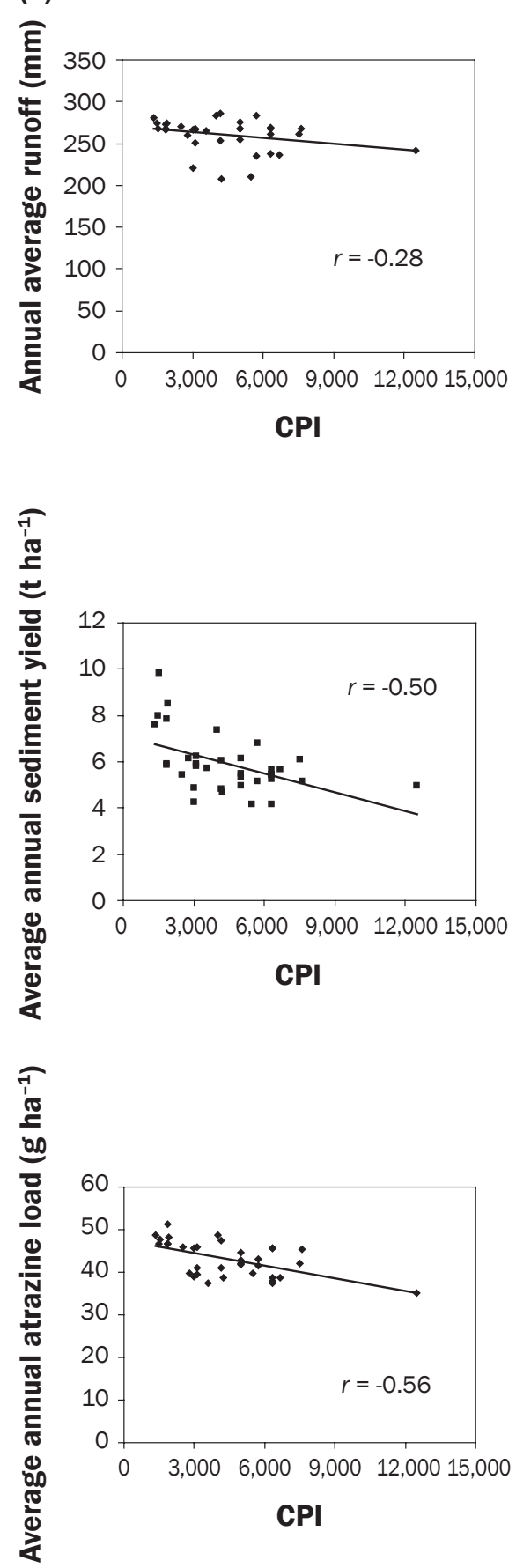

(b)
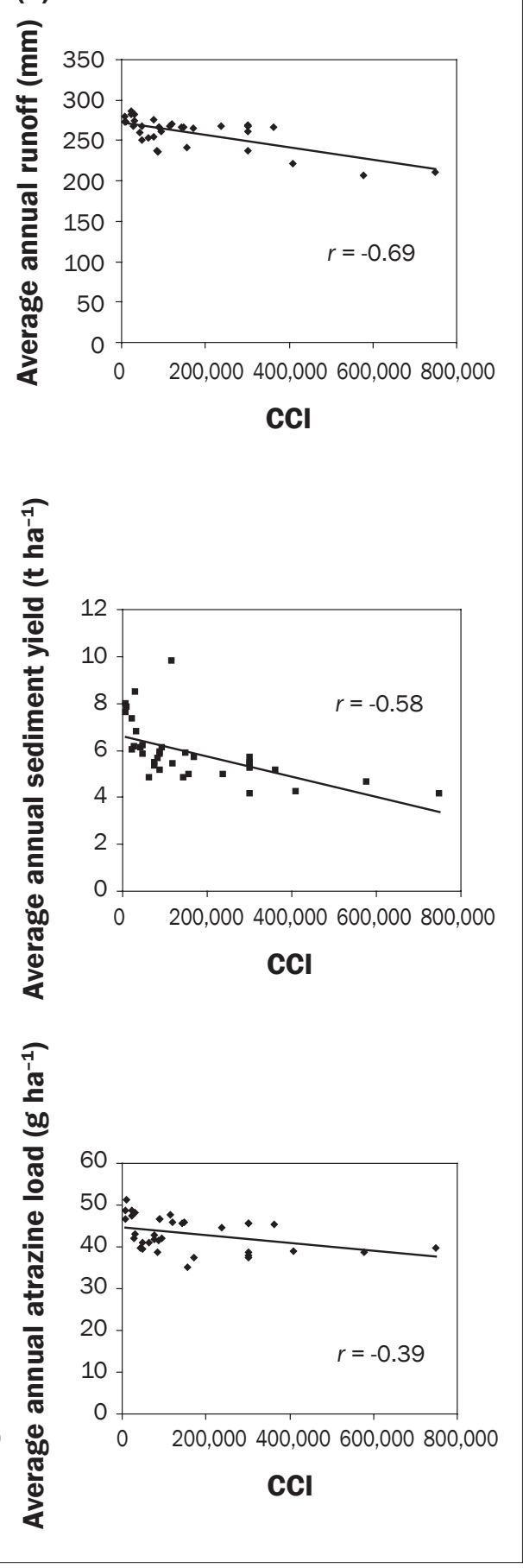

and 33. Management zone B, the most productive area in the field, encompasses both the drainage channel and the foot slope position in this field (Subareas 19, 24, 25, and 33). Management zone $\mathrm{C}$ includes approximately the southern half of the field and represents the broad summit and some shoulder landscape position soils where profitability has generally been positive. The simulation results obtained with APEX confirm the productiv- ity results but also indicate that, along with lower crop yields, the back slope areas on either side of the channel present a higher environmental risk in terms of sediment loss and atrazine transport (figure 7).

Since runoff, sediment, and atrazine are all important, the critical areas based on these three simulated variables were combined to form the APEX-based CMAs. Similarly, because simulated runoff, sediment, and atrazine are better correlated with one or the other index, CPI and CCI critical areas were combined to form the index-based CMAs. The final APEX and index critical areas are shown in figure 8 . Index-based CMAs delineated by using the index-based technique included 20.9 ha $(51.7 \mathrm{ac})$ and captured $71 \%$ of the 20.8 ha $(51.4 \mathrm{ac})$ of CMAs delineated using model outputs. In addition, the indices captured 2.8 ha $(6.9 \mathrm{ac})$ that were not found critical based on model results. Indexbased delineation captured $100 \%$ of CMAs for runoff and sediment yield and 60\% for atrazine load.

The Jenks algorithm was used in this study to classify subareas based on their APEX simulated output variables and on the values of the indices. The threshold values that differentiate critical areas from noncritical ones are a result of this classification method, are specific to this field, and could not be directly applied to another one, nor could they be directly applied to a larger watershed. The methodology proposed here was designed to find the most critical areas in the field. It resulted in a good match between results obtained with the APEX model and the indices. Other methods, such as dividing subareas based on log scale, defining intervals manually, or using a multiple of the standard deviation, did not produce consistent results when based on APEX results and on indices. In this case study, using the two most extreme classes out of the five classes resulted in critical areas consistent with the least productive areas of the field as determined by Massey et al. (2008). Ultimately, the number of classes used in the classification and the determination of how many are deemed critical should be defined in relation to water quality objectives, production and profitability goals, and availability of resources for soil and water conservation.

Best Management Practices and Simulation Scenario Analyses. The 30-year annual average runoff, sediment yield, and atrazine load were estimated for all the simu- 


\section{Figure 6}

Critical management areas (CMAs) delineated in the field using two indices-(a) Claypan Index (CPI) and (b) Conductivity Claypan Index (CCl). The shaded regions in each map were the lowest two classes when classified into five classes by the Jenks optimization technique.

(a)

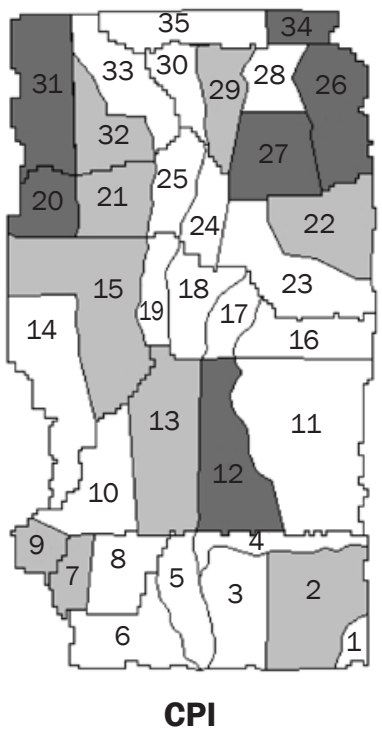

Legend

$<1,923$

1,923 to 3,572

$>3,572$ (b)

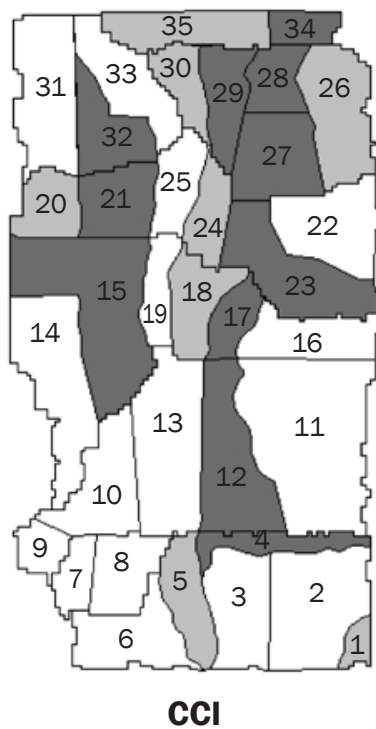

Legend

$<48,125$

48,125 to 93,750

$>93,750$

\section{Table 2}

Coefficients of correlation $(r)$ between measured and simulated crop yields and indices for the 35 subareas.

\begin{tabular}{lcc}
\hline Crop & $\boldsymbol{r}$-value with CPI & $\boldsymbol{r}$-value with $\mathbf{C C I}$ \\
\hline Measured & & \\
\hline Corn & $\star 0.46$ & $* 0.39$ \\
Soybean & 0.21 & -0.17 \\
\hline Simulated & & $* 0.62$ \\
\hline Corn & $* 0.68$ & $* 0.33$ \\
Soybean & 0.22 &
\end{tabular}

Notes: $\mathrm{CPI}=$ Claypan Index. $\mathrm{CCl}=$ Conductivity Claypan Index.

* Values greater than 0.28 are significant.

lated scenarios. Scenarios 1,2 , and 4 were able to significantly reduce sediment and atrazine loads in comparison to the baseline (table 3). Replacing the corn-soybean rotation with a soybean-wheat rotation (scenario 3 ) was expected to reduce runoff, sediment yield, and atrazine load in two ways: elimination of atrazine load because there would be no application of atrazine and reduction of runoff and sediment loss because wheat has a longer growing period in comparison to corn and provides ground cover during the winter and early spring. However, simulation results suggested there was no significant change in sediment yield $(-5 \%)$ or in surface runoff $(5 \%)$ in comparison to the baseline. A necessary component of that rotation, and one which was not simulated in this study, may be the use of a cover crop after the wheat is harvested. Without one, there is no uptake of water during the summer, fall, and winter that follow wheat harvest, which usually occurs in late June. Thus, any benefit from wheat providing ground cover and water uptake during the winter and early spring may be countered by the lack of water uptake following its harvest.

The two most effective scenarios for sediment load reduction were the establishment of a filter strip (scenario 2) just before the field outlet and planting grasses (scenario 4) in the channel subareas (subareas 19, 25, 33, and 35). Establishment of a filter strip of fescue grass just before the field outlet was able to reduce runoff, sediment yield, and atrazine loads significantly in comparison to the baseline. The impact of filter strips in reducing runoff and NPS pollutants is well documented in the literature (Gilliam 1994; Udawatta et al. 2002; Lovell and Sullivan 2006; Kumar et al. 2008). The model is able to predict flow and sediment reductions from grass areas through different processes: grasses dewater the profile in the spring rather than later in the summer; the curve number for grasses is lower than for row crops; grasses provide groundcover throughout the year, which reduces soil erosion; and finally, the overland and channel Manning coefficients are lower and result in slower flow and lower sediment transport capacity. In APEX, the reduction in atrazine loadings results only from infiltration of runon from upstream areas into the filter strip. Thus the predicted reduction is of the same magnitude as the runoff reduction. Lin et al. (2008) did a lysimeter study in Missouri to ascertain the impact of filter strips in reducing atrazine by degrading it to lower toxicity metabolites. They found that switchgrass converted $80 \%$ of atrazine into less toxic metabolites and 47\% less mobile by-products. Therefore, filter strips not only reduce the mobility but also the toxicity of pollutants. This phenomenon is not simulated by APEX.

Planting switchgrass in the channel subareas (scenario 4) may be attractive to farmers in that it offers the possibility of production income. Although not simulated as a filter strip, warm season grasses acted as one, trapping sediment and taking water out of the soil profile during the wettest part of the year (Schilling et al. 2008). They also provided ground cover throughout the year, which reduced soil and channel bank erosion.

In scenario 1 , in which the model delineated CMAs were targeted to switchgrass, there was a reduction of $16 \%, 48 \%$, and $70 \%$ in runoff, sediment yield, and atrazine load respectively. When index delineated CMAs were targeted, there was a reduction of $11 \%$, 


\section{Figure 7}

Spatial distribution of ( $a$ and c) simulated and ( $b$ and $d$ ) measured annual average crop yield from 1993 to 2002. The shaded regions in each map were the lowest two classes of crop yields when classified into five classes by the Jenks optimization technique.

(a)

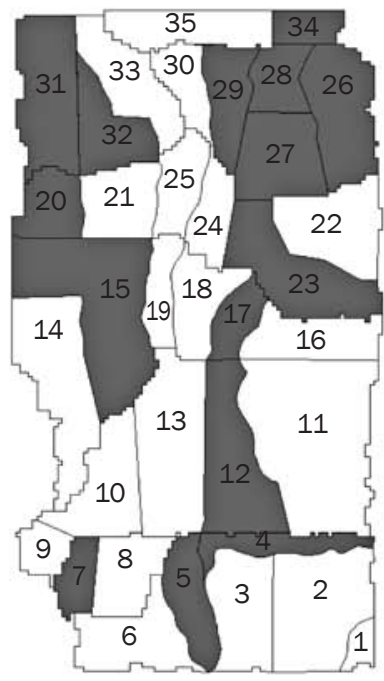

Corn simulated yield

\section{Legend}

4.42 to $5.60 \mathrm{t} \mathrm{ha}^{-1}$ 5.60 to $7.61 \mathrm{t} \mathrm{ha}^{-1}$

(c)

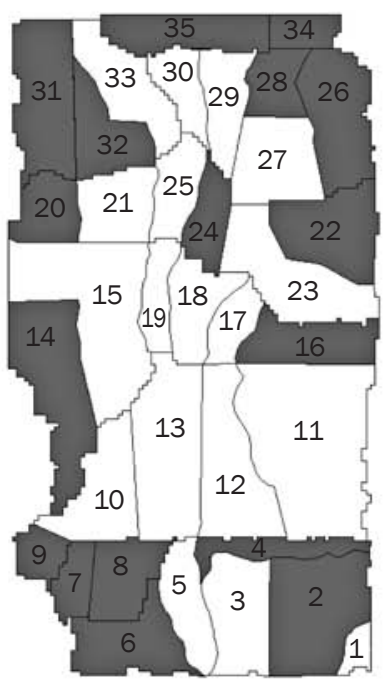

Soybean simulated yield

Legend

1.74 to $2.06 \mathrm{t} \mathrm{ha}^{-1}$ 2.06 to $2.56 \mathrm{t} \mathrm{ha}^{-1}$ (b)

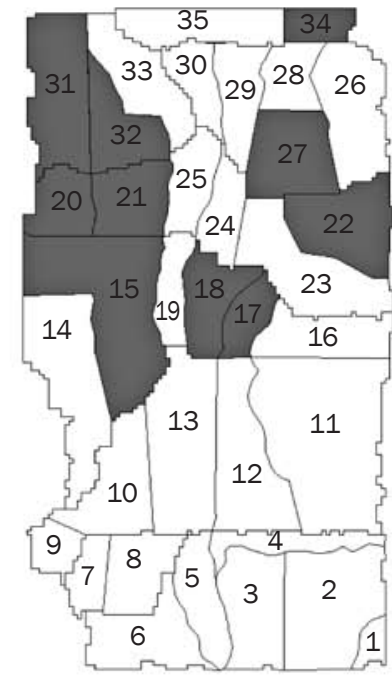

\section{Corn measured yield}

\section{Legend}

4.84 to $5.60 \mathrm{tha}^{-1}$ 5.60 to $6.53 \mathrm{t} \mathrm{ha}^{-1}$

(d)

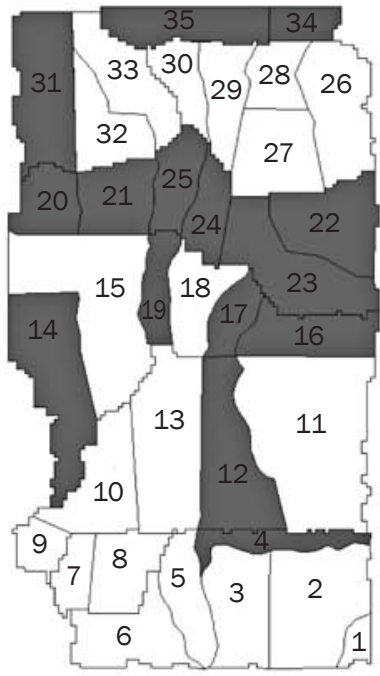

Soybean measured yield

\section{Legend}

2.11 to $2.25 \mathrm{t} \mathrm{ha}^{-1}$ 2.25 to $2.53 \mathrm{t} \mathrm{ha}^{-1}$
$34 \%$, and $51 \%$ in runoff, sediment yield, and atrazine load respectively. While the treated areas were slightly different with the modeland index-based techniques, total land area treated with either method was $66 \%$ of the field, leaving only one third of the field in grain production. Given the uncertainty in model performance for sediment, we also investigated the atrazine loading reductions predicted by the model if the only targeted areas were those delineated as critical for atrazine or runoff. In that case, atrazine loadings would be reduced by $55 \%$, which would still be a significant reduction from the baseline scenario.

Scenario 1 would not only lead to increased atrazine load reductions at the outlet but may also have extended economic benefits. As shown in figure 7 , the critical areas correlate with areas of lowest corn and soybean yields. Yet the field is managed in a uniform manner, which leads to lower profits or even losses in these critical areas. This was established earlier by Massey et al. (2008) by looking at the spatial distribution of profits over a 10-year period. Growing alternative crops that bring sustained profits year after year would decrease the economic risk of farming this field. This study suggests that growing switchgrass or small grain crops may be suitable. High yielding and profitable areas (channel subareas and south end of the field) could remain in grain production. Enrollment in the Conservation Reserve Program or the near-future potential for income derived from grasses used for bioenergy could provide the needed financial incentives to achieve a conversion from grain to forage production.

\section{Summary and Conclusions}

The present study was conducted to delineate CMAs in a 32 ha $(80 \mathrm{ac})$ field located in the Goodwater Creek Experimental Watershed, with predominant soils classified as claypan soils (fine, smectitic, mesic, Aeric Vertic Epiaqualfs and Vertic Albaqualfs). The field was divided into 35 subareas based on topography, CD, and soil type. The APEX model was calibrated and validated for runoff, sediment yield, and atrazine load at the field outlet, from 1993 to 2002. The model was able to simulate runoff and atrazine within acceptable limits. The sediment validation results were not satisfactory, which could have been due to different causes, includ- 
Table 3

Scenarios with best management practices (BMPs) applied and 30-year (1979 to 2008) simulation results of annual average runoff, sediment yield, and atrazine load.

\begin{tabular}{|c|c|c|c|c|c|c|c|}
\hline \multirow[b]{2}{*}{ Scenario } & \multirow[b]{2}{*}{ Best management practices } & \multicolumn{2}{|c|}{ Runoff } & \multicolumn{2}{|c|}{ Sediment yield } & \multicolumn{2}{|c|}{$\begin{array}{l}\text { Dissolved atrazine load } \\
\text { in surface runoff }\end{array}$} \\
\hline & & $\mathbf{m m}$ & $\%$ change & $t_{\text {ha }}$-1 $^{2}$ & $\%$ change & $\mathrm{g} \mathrm{ha}^{-1}$ & $\%$ change \\
\hline \multirow[t]{3}{*}{1} & $\begin{array}{l}\text { All the CMAs were cropped with switchgrass, } \\
\text { and the rest of the field was left under } 1991 \text { to } \\
2002 \text { crop management. Based on the CMAs } \\
\text { targeted, this scenario was further divided into } \\
\text { two parts: }\end{array}$ & & & & & & \\
\hline & a. CMAs delineated by model-based technique. & 184 & -16 & $4.6^{*}$ & -48 & $3.0 *$ & -70 \\
\hline & b. CMAs delineated by index-based technique. & 196 & -11 & $5.8^{*}$ & -34 & $4.9 *$ & -51 \\
\hline 2 & $\begin{array}{l}\text { One hectare area immediately before the field outlet } \\
\text { was managed as filter strip, and the rest of the } \\
\text { field with } 1991 \text { to } 2002 \text { crop management. }\end{array}$ & $140 *$ & -37 & $3.3^{*}$ & -63 & 6.6 & -35 \\
\hline 4 & $\begin{array}{l}\text { Subareas that included the main channel of the } \\
\text { field were put under switchgrass, and the rest of } \\
\text { the field was left under } 1991 \text { to } 2002 \text { crop management. }\end{array}$ & $136 *$ & -38 & $3.2^{*}$ & -64 & $5.3 *$ & -48 \\
\hline
\end{tabular}

\section{Figure 8}

Critical management areas (CMAs) delineated using (a) APEX model outputs and (b) indices (Claypan Index and Conductivity Claypan Index).

(a)

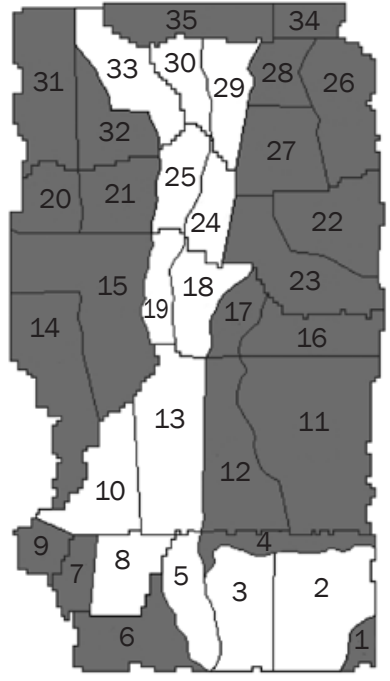

APEX delineated CMAs

\section{Legend}

Noncritical

Critical (b)

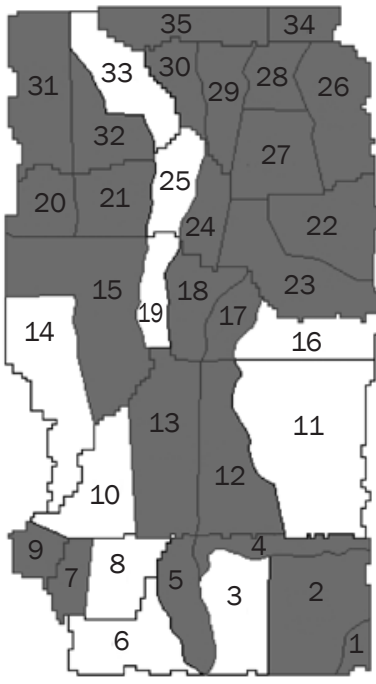

Index delineated CMAs

\section{Legend}

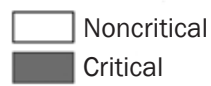

ing some changes in soil properties during the simulation period. The simulated crop yields were also compared to measured ones to verify the spatial variability of the model's response. Results showed that simulated corn yields varied as a result of variability in saturated hydraulic conductivity and CD throughout the field, which control water availability. Soybean yields did not respond to these properties and may respond to different processes than corn.

The average annual runoff, sediment yield, atrazine load, and corn and soybean yields were estimated for all 35 subareas during the total simulation period. Based on Jenks optimization technique, all the outputs were divided into five different classes, and the subareas that produced the highest amounts of runoff, sediment yield, and atrazine load were considered as CMAs. All three approaches used for delineating CMAs resulted in $66 \%$ of the field being designated as critical areas. Twenty percent of the total field area was found to be critical because of excess runoff generation, $27 \%$ due to atrazine load, and 35\% due to sediment yield.

The values of the two indices developed for delineating CMAs, CPI, and CCI were found to significantly correlate to runoff, atrazine, and sediment average annual values calculated by the APEX model. Therefore, 
these indices were also used to identify CMAs in the field. Index-based delineation of CMAs captured $71 \%$ of the CMAs delineated by the model simulation technique. We conclude that further investigations are warranted to determine whether these two indices, CPI and CCI, can be used for delineating CMAs in claypan areas without the use of complex hydrologic models.

The scope of the present study was limited to one field-scale study using fine scale elevation and soil data. While the field-scale size of the study is the relevant scale at which most BMPs are implemented, these highresolution elevation and soil data are not yet widely available to the USDA Natural Resources Conservation Service in charge of assisting farm managers and landowners to implement these BMPs. Behavior of these indices using coarser data such as the USDA Natural Resources Conservation Service Soil Survey Geographic soil database (SSURGO; 1:24000 scale) and USGS DEM is presently undetermined. If these indices can be shown to accurately delineate CMAs using the coarser scale data, they could be applied to the watershed scale in claypan regions. In addition, there is a need to investigate the effects of the classification scheme used to select CMAs; alternative methods should be investigated at this and larger scales.

This study demonstrated that APEX could represent the spatial variability of the soil properties in this field and reflect the effects of this variability in the simulated corn yields. The model results imply that the most critical areas in terms of environmental risk also have poor corn production, thus indicating that crop production may be a useful indicator of the environmental risk associated with hydrologic transport of contaminants. While this simulation study would benefit from experimental verification of the conclusions related to higher amounts of runoff, sediment yield, and atrazine load from CMAs, the model can be used to design new agricultural practices that take into account these production and environmental risks. The alternative scenarios considered in this study can be refined to consider practical aspects of farming in this field and economic considerations. The results indicate that some practices may be able to protect water quality and lead to more sustainable agricultural production.

\section{References}

Beven, K.J., and M.J. Kirkby. 1979. A physically based variable contributing area model of basin hydrology. Hydrological Sciences Bulletin 24(1):43-69.

Blanco-Canqui, H., C.J. Gantzer, S.H.Anderson, E.E.Alberts, and F. Ghidey. 2002. Saturated hydraulic conductivity and its impact on simulated runoff for claypan soils. Soil Science Society of America Journal 66(5):1596-1602.

Busteed, P.R., D.E. Storm, M.J. White, and S.H. Stoodley. 2009. Using SWAT to target critical source sediment and phosphorous areas in the Wister Lake Basin, USA. American Journal of Environmental Sciences 5(2):156-163.

Dendy, F.E., P.B. Allen, and R.F. Piest. 1979. Chapter 4. Sedimentation. In Field manual for research in agricultural hydrology, eds. D.L. Brakensiek, H. B. Osborn, and W.J. Rawls. Agriculture Handbook No. 224. Washington, DC: USDA, Science and Education Administration.

Easton, Z.M., M.T. Walter, and T.S. Steenhuis. 2008 Combined monitoring and modeling indicate the most effective agricultural best management practices. Journal of Environmental Quality 37:1798-1809.

Endreny, T.A., and E.F. Wood. 2003. Watershed weighing of export coefficients to map critical phosphorous loading areas. Journal of the American Water Resources Association 39(1):165-181.

Fraisse, C.W., K.A. Sudduth, and N.R. Kitchen. 2001 Delineation of site-specific management zones by unsupervised classification of topographic attributes and soil electrical conductivity. Transactions of the American Society of Agricultural Engineers 44(1):155-166.

Gassman, P.W., J.R.Williams, X.Wang,A. Saleh, E. Osei, L.M. Hauck, R.C. Izaurralde, and J.D. Flowers. 2010. The Agricultural Policy Environmental Extender (APEX) model: An emerging tool for landscape and watershed environmental analyses. Transactions of the American Society of Agricultural and Biological Engineers 53(3):711-740.

Gburek, W.J., A.N. Sharpley, A.L. Heathwaite, and G.J Folmar. 2000. Phosphorus management at the watershed scale:A modification of the phosphorus index. Journal of Environmental Quality 29:130-144(1).

Ghidey, F., E.E. Alberts, and R.N. Lerch. 1997. Spatial and temporal variability of herbicides in a claypan soil watershed. Journal of Environmental Quality 26(6):1555-1563.

Ghidey, F., and E.E. Alberts. 1999. Temporal and spatial patterns of nitrate in claypan soils. Journal of Environmental Quality 28(2):584-594.

Ghidey, F., P.E. Blanchard, R.N. Lerch, E.E. Alberts, and E.J. Sadler. 2005. Measurement and simulation of herbicide transport from the corn phase of three cropping systems. Journal of Soil and Water Conservation 60(5):260-273.

Ghidey, F., C. Baffaut, R.N. Lerch, N.R. Kitchen, E.J. Sadler, and K.A. Sudduth. 2010. Herbicide transport to surface runoff from a claypan soil: Scaling from plots to fields.
Journal of Soil and Water Conservation 65(3):168-179, doi:10.2489/jswc.65.3.168.

Gilliam, J.W. 1994. Riparian wetlands and water quality. Journal of Environmental Quality 23(5):896-900.

Grabs,T., J. Seibert, K. Bishop, and H. Laudon. 2009. Modeling spatial patterns of saturated areas: A comparison of the topographic wetness index and a dynamic distributed model. Journal of Hydrology 373(1-2):15-23.

Harman, W.L., E. Wang, and J.R. Williams. 2004. Reducing atrazine losses: Water quality implications of alternative runoff control practices. Journal of Environmental Quality 33(1):7-12.

Heathwaite, L., A. Sharpley, and W. Gburek. 2000. A conceptual approach for integrating phosphorus and nitrogen management at watershed scales. Journal of Environmental Quality 29(1):158-166.

Hewlett, J.D., and A.R. Hibbert. 1967. Factors affecting the response of small watersheds to precipitation in humid regions. In Forest Hydrology, eds. W.E. Sopper and H.W. Lull, pp. 275-290. Oxford: Pergamon Press.

Hjerdt, K.N., J.J. McDonnell, J. Seibert, and A. Rodhe. 2004. A new topographic index to quantify downslope controls on local drainage. Water Resources Research 40,W05602, doi:10.1029/2004WR003130.

Ibbitt, R., and R. Woods. 2004. Re-scaling the topographic index to improve the representation of physical processes in catchment models. Journal of Hydrology 293(1-4):205-218.

Inamdar, S.P., S. Mostaghimi, M.N. Cook, K.M. Brannan, and P.W. McClellen. 2002. A long-term watershed scale, evaluation of the impacts of animal waste BMPs on indicator bacteria concentrations. Journal of the American Water Resources Association 38(3):819-833.

Jenks, G.F. 1967. The data model concept in statistical mapping. International Yearbook of Cartography 7:186-190.

Jiang, P., S.H. Anderson, N.R. Kitchen, K.A. Sudduth, and E.J. Sadler. 2007. Estimating plant-available water capacity for claypan landscapes using apparent electrical conductivity. Soil Science Society of America Journal 71(6):1902-1908.

Jung, W.K., N.R. Kitchen, K.A. Sudduth, R.J. Kremer, and P.P. Motavalli. 2005. Relationship of apparent soil electrical conductivity to claypan soil properties. Soil Science Society of America Journal 69(3):883-892.

Kachanoski, R.G., E.G. Gregorich, and I.J.Van Wesenbeeck. 1988. Estimating spatial variations of soil water content usingnon-contacting electromagnetic inductive methods. Canadian Journal of Soil Science 68:715-722.

Kaps, M., and W. Lamberson. 2007. Chapter 6: Hypothesis testing. In Biostatistics for animal science, 76-79. Cambridge, MA: CABI Publishing.

Kitchen, N.R., K.A. Sudduth, and S.T. Drummond. 1999. Soil electrical conductivity as a crop productivity measure for claypan soils. Journal of Production Agriculture 12(4):607-617. 
Kitchen, N.R., K.A. Sudduth, D.B. Myers, S.T. Drummond, and S.Y. Hong. 2005a. Delineating productivity zones on claypan soil fields using apparent soil electrical conductivity. Computers and Electronics in Agriculture 46(1-3):285-308.

Kitchen, N.R., K.A. Sudduth, D.B. Myers, R.E. Massey, E.J Sadler, R.N. Lerch, J.W. Hummel, and H.L. Palm. 2005b. Development of a conservation-oriented precision agriculture system: Crop production assessment and plan implementation. Journal of Soil and Water Conservation 60(6):421-430.

Krause, P., D.P. Boyle, and F. Base. 2005. Comparison of different efficiency criteria for hydrological model assessment. Advances in Geosciences, 5:89-97.

Kumar, S., S.H. Anderson, L.G. Bricknell, R.P. Udawatta, and C.J. Gantzer. 2008. Soil hydraulic properties influenced by agroforestery and grass buffers for grazed pasture systems. Journal of Soil and Water Conservation 63(4):224-232, doi:10.2489/jswc.63.4.224.

Lerch, R.N., N.R. Kitchen, R.J. Kremer, W.W. Donald, E.E. Alberts, E.J. Sadler, K.A. Sudduth, D.B. Myers, and F. Ghidey. 2005. Development of a conservation-oriented precision agriculture system: Water and soil quality assessment. Journal of Soil and Water Conservation 60(6):411-420.

Lin, C.H., R.N. Lerch, H.E. Garrett, and M.F. George. 2008. Bioremediation of atrazine-contaminated soil by forage grasses: Transformation, uptake, and detoxification. Journal of Environmental Quality 37(1):196-206.

Line, D.E., and J. Spooner. 1995. Critical areas in agricultural nonpoint source pollution control projects: the rural clean water program experience., Rural Clean Water Technology Transfer Fact sheet No.5. Raleigh, NC: NCSU Water Quality Group, North Carolina Cooperative Extension Service, Department of Biological and Agricultural. Engineering, North Carolina State University.

Lovell, S.T., and W.C. Sullivan. 2006. Environmental benefits of conservation buffers in the United States: Evidence, promise, and open questions. Agriculture Ecosystems and Environment 112:249-260.

Massey, R.E., D.B. Myers, N.R. Kitchen, and K.A. Sudduth. 2008. Profitability maps as an input for site-specific management decision making. Agronomy Journal 100:52-59.

Meals, D.W., S.A. Dressing, and T.E. Davenport. 2010. Lag time in water quality response to best management practices: A review. Journal of Environmental Quality 39:85-96.

Moriasi, D.N., J.G. Arnold, M.W. Van Liew, R.L. Bingner, R.D. Harmel, and T.L. Veith. 2007. Model evaluation guidelines for systematic quantification of accuracy in watershed simulations. Transactions of the American Society of Agricultural and Biological Engineers 50:885-900.

Mudgal, A., S.H. Anderson, C. Baffaut, N.R. Kitchen, and E.J. Sadler. 2010a. Effects of long-term soil and crop management on soil hydraulic properties for claypan soils. Journal of Soil and Water Conservation 65(6):393403, doi:10.2489/jswc.65.6.393.

Mudgal, A., C. Baffaut, S.H. Anderson, E.J. Sadler, and A.L. Thompson. 2010b. APEX model assessment of variable landscapes on runoff and dissolved herbicides. Transactions of the American Society of Agricultural and Biological Engineers 53(4):1047-1058.

Nash, J.E., and J.E. Sutcliffe. 1970. River flow forecasting through conceptual models: Part 1. A discussion of principles. Journal of Hydrology 10:282-290.

Park, S.W., S. Mostaghimi, R.A. Cook, and P.W. McClellan. 1994. BMP impacts on watershed runoff, sediment and nutrient yields. Journal of the American Water Resources Association 30(6):1011-1023.

Paudel, K.P., D. Hite, W. Intarapapong, and D. Susanto. 2003. A watershed-based economic model of alternative management practices in southern agricultural systems. Journal Agricultural and Applied Economics 35(2):381-389.

Qiu, Z., T. Prato, L. Godsey, and V. Benson. 2002. Integrated assessment of uses of woody draws in agricultural landscapes. Journal of the American Water Resources Association 38(5):1255-1269.

Ramanarayanan, T.S., J.R.Williams, W.A. Dugas, L.M. Hauck, and A.M.S. McFarland. 1997. Using APEX to identify alternative practices for animal waste management. Paper number 972209 presented at the American Society of Agricultural Engineers Annual International Meeting, Minneapolis, Minnesota, August 10-14, 1997. St. Joseph, MI: American Society of Agricultural Engineers.

Rhoades, J.D., P.A. Raats, and R.J. Prather. 1976. Effects of liquid-phase electrical conductivity, water content, and surface conductivity on bulk soil electrical conductivity. Soil Science Society of America Journal 40:651-655.

Sadler, E.J., R.N. Lerch, E.E. Alberts, and T.L. Oster. 2006. Long-term hydrologic database: Goodwater Creek, Missouri. In Fowler, D.L. compiler, Proceedings of the 2nd Interagency Conference on Research in the Watersheds, May 16-17, 2006. Otto, NC: Coweeta Hydrologic Laboratory.

Saleh, A., J.R. Williams, J.C. Wood, L.M. Hauck, and W.H. Blackburn. 2004. Application of APEX for forestry. Transactions of the American Society of Agricultural Engineers 47(3):751-765.

Santhi, C., J.G. Arnold, J.R. Williams, W.A. Dugas, R. Srinivasan, and L.M. Hauck. 2001. Validation of the SWAT model on a large river basin with point and nonpoint sources. Journal of the American Water Resources Association 37(5):1169-1188.

SAS. 1999. SAS User's Guide: Statistics. SAS Institute, Cary, NC: SAS Institute Inc.

Saxton, K.E.,W.J. Rawls, J.S. Romberger, and R.I. Papendick. 1986. Estimating generalized soil-water characteristics from texture. Soil Science Society of America Journal 50:1031-1036
Simpson, T.W., and S.E. Weammert. 2008. Revising BMP efficiencies for the Chesapeake Bay watershed: Challenges and lessons learned. In 21st Century Watershed Technology: Improving Water Quality and Environment Conference Proceedings, eds. E.W.Tollner and A. Saleh, Concepcion, Chile, 29 March - 3 April 2008. St. Joseph, MI: American Society of Agricultural and Biological Engineers.

Schilling, K.E., M.K. Jha, Y.K. Zhang, P.W. Gassman, and C.F. Wolter. 2008. Impact of land use and land cover change on the water balance of a large agricultural watershed: Historical effects and future directions. Water Resources Research 44(7):W00A09

Sorensen, R.,U.Zinko, and J.Seibert. 2006. On the calculation of the topographic wetness index: evaluation of different methods based on field observations. Hydrology and Earth System Sciences 10:101-112.

Srinivasan, M.S., P.G. Marchant, T.L.Veith, W.J. Gburek, and T.S. Steenhuis. 2005. Watershed scale modeling of critical source areas of runoff generation and phosphorous transport. Journal of the American Water Resources Association 41(2):361-375.

Srivastava, P., K.W. Migliaccio, and J. Simunek. 2007 Landscape models for simulating water quality at point, field, and watershed scales. Transactions of the American Society of Agricultural and Biological Engineers 50(5):1683-1693.

Steglich, E.M., and J.R. Williams. 2008. Agricultural Policy/Environmental eXtender Model: User's manual. Version 0604 DOS and WINAPEX interface. BREC Report \# 2008-16. Temple, TX: Texas AgriLIFE Research, Texas A\&M University, Blackland Research and Extension Center.

Sudduth, K.A., N.R. Kitchen, G.A. Bollero, D.G. Bullock, and W.J. Wiebold. 2003. Comparison of electromagnetic induction and direct sensing of soil electrical conductivity. Agronomy Journal 95(3):472-482.

Sudduth, K.A., N. R.Kitchen, W.J. Wiebold, W.D. Batchelor, G.A. Bollero, D.G. Bullock, D.E. Clay, H.L. Palm, FJ. Pierce, R.T. Schuler, and K.D. Thelen. 2005. Relating apparent electrical conductivity to soil properties across the north-central USA. Computers and Electronics in Agriculture 46(1-3):263-283.

Sudduth, K.A., and N.R. Kitchen. 2006. Increasing information with multiple soil electrical conductivity datasets. Paper No. 061055. In Proceedings of the American Society of Agricultural and Biological Engineers Annual International Meeting. St. Joseph, MI: American Society of Agricultural and Biological Engineers.

Sudduth, K.A., and S.T. Drummond. 2007. Yield editor: Software for removing errors from crop yield maps. Agronomy Journal 99(6):1479-1482.

Sudduth, K.A., N.R. Kitchen, D.B. Myers, and S.T. Drummond. 2010. Mapping depth to argillic soil horizons using apparent electrical conductivity. Journal of Environmental and Engineering Geophysics 15(3):135-146. 
Thompson, A.L., C.J. Gantzer, and S.H. Anderson. 1991. Topsoil depth, fertility, water management, and weather influences on yield. Soil Science Society of America Journal 55:1085-1091.

Tomer,M.D.,D.E.James, and T.M. Isenhart. 2003. Optimizing the placement of riparian practices in a watershed using terrain analysis. Journal of Soil and Water Conservation 58(4):198-206.

Udawatta, R.P., J.J. Krstansky, G.S. Henderson, and H.E. Garrett. 2002. Agroforestry practices, runoff, and nutrient loss: A paired watershed comparison. Journal of Environmental Quality 31:1214-1225.

USDA NRCS (Natural Resources Conservation Service). 2006. Land Resources Regions and Major Land Resource Areas of the United States, the Caribbean, and the Pacific Basin. US Department of Agriculture Handbook 296. Washington, DC: USDA Natural Resources Conservation Service.

Walter, M.T., M.F. Walter, E.S. Brooks, T.S. Steenhuis, J. Boll, and K. Weiler. 2000. Hydrological sensitive areas:Variable source area hydrology implications for water quality risk assessment. Journal of Soil and Water Conservation 55(3):277-284.

Wang, X., and P. Cui. 2005. Support soil conservation practices by identifying critical erosion areas within an American watershed using the GIS-AGNPS model. Journal of Spatial Hydrology 5(2):31-44.

Wang, X., S.R. Potter, J.R. Williams, J.D. Atwood, and T. Pitts. 2006. Sensitivity analysis of APEX for national assessment. Transactions of the American Society of Agricultural and Biological Engineers 49(3):679-688.

Wang, X.,A. Saleh, M.W. McBroom, J.R.Williams, and L.Yin. 2007. Test of APEX for nine forested watersheds in East Texas. Journal of Environmental Quality 36:983-995.

Wang, X., J.R. Williams, and W.E. Fox. 2009. Modeling the effectiveness of conservation practices at Shoal Creek Watershed, Texas using APEX. Transactions of the American Society of Agricultural and Biological Engineers 52(4):1181-1192.

Williams, J.R. 1995. The EPIC model. In Computer Models of Watershed Hydrology V. P. Singh, ed., 909-1000. Highlands Ranch, CO: Water Resources Publications.

Williams, J.R.,W.L. Harman, M. Magre, U. Kizil, J.A. Lindley, G. Padmanabhan, and E. Wang. 2006. APEX feedlot water quality simulation. Transactions of the American Society of Agricultural and Biological Engineers 49(1):61-73.

Williams, J.R., R.C. Izaurralde, and E.M. Steglich. 2008. Agricultural Policy/Environmental eXtender Model: Theoretical documentation. Version 0604. BREC Report \# 2008-17. Temple, TX: Texas AgriLiFE Research, Texas A\&M University, Blackland Research and Extension Center.

Willis, D. B. 2008. Cost-effectiveness of on-farm conservation practices to protect Playa Lake hydroperiod in the Texas High Plains. Paper presented at the Southern
Agricultural Economics Association Annual Meeting, Dallas, TX, February 3-6, 2008.

Yin, L., X. Wang, J. Pan, and P.W. Gassman. 2009. Evaluation of APEX for daily runoff and sediment yield from three plots in the Upland Huaihe River watershed, China. Transactions of the American Society of Agricultural and Biological Engineers 52(6):1833-1845.

Young, R.A., C.A. Onstad, D.D. Bosch, and W.P. Anderson. 1989. AGNPS: A nonpoint-source pollution model for evaluating watersheds. Journal of Soil and Water Conservation 44(2):168-173. 